Canadian University Music Review

Revue de musique des universités canadiennes

\title{
Violet Archer's Formative Years: A Bibliographical Catalogue of Her Compositions, 1932-43
}

\section{James Whittle}

Volume 16, numéro 1, 1995

Voices of Women: Essays in Honour of Violet Archer

Voix de femmes : mélanges offerts à Violet Archer

URI : https://id.erudit.org/iderudit/1014421ar

DOI : https://doi.org/10.7202/1014421ar

Aller au sommaire du numéro

\section{Éditeur(s)}

Canadian University Music Society / Société de musique des universités canadiennes

\section{ISSN}

0710-0353 (imprimé)

2291-2436 (numérique)

Découvrir la revue

Citer ce document

Whittle, J. (1995). Violet Archer's Formative Years: A Bibliographical Catalogue of Her Compositions, 1932-43. Canadian University Music Review / Revue de musique des universités canadiennes, 16(1), 145-195.

https://doi.org/10.7202/1014421ar

\section{Résumé de l'article}

This chronological catalogue of Violet Archer's earliest completed compositions, including works written from 1932 to 1943, is based on manuscripts in her possession and on deposit at the University of Calgary Library, as well as published scores and reproductions of manuscripts in the University of Alberta Library and the libraries of the Canadian Music Centre. It provides the date of composition for each work and summarizes the supporting evidence, including dates found on manuscripts, the types of paper used, entries on lists of works compiled by the composer, and dates of first and early performances. Also included are the medium of performance of each work, a list of movements, the source of any text, and the location of scores and recordings.
All Rights Reserved (C Canadian University Music Society / Société de musique des universités canadiennes, 1995
Ce document est protégé par la loi sur le droit d'auteur. L’utilisation des services d'Érudit (y compris la reproduction) est assujettie à sa politique d'utilisation que vous pouvez consulter en ligne.

https://apropos.erudit.org/fr/usagers/politique-dutilisation/ 


\title{
VIOLET ARCHER'S FORMATIVE YEARS: A BIBLIOGRAPHICAL CATALOGUE OF HER COMPOSITIONS, 1932-43
}

\author{
James Whittle
}

In the fall of 1979, about a year after her retirement from full-time teaching at the University of Alberta, Violet Archer began to keep a list of her new compositions. Since that time, works have been added as they were completed, and the list periodically retyped, with the result that it provides an eyewitness account of her creative activity over the past fifteen years. Archer's career as a composer, however, now spans nearly sixty years, during which she has produced more than three hundred compositions; and for the larger part of that time, no journalistic record exists. For the years immediately preceding 1979 , other documentation is available. This includes the accession lists of the Canadian Music Centre and SOCAN's computerized records of the registration of her works with its predecessor societies, BMI Canada and PRO Canada, which together provide the basis for constructing a chronological list for the 1960 s and 1970s. But for the period before 1960 , and particularly for the decades of the 1930s and 1940s, the public record of Archer's output is neither accurate nor complete.

This study seeks to reconstruct the chronological record for the earliest part of Archer's career, her years as a student in Montreal. A newspaper clipping and a transcript in her files document the major academic milestones of that period. The clipping, from page 14 of The Montreal Daily Star for 24 July 1930, reports the results of the provincial "High School Leaving Examinations" for June 1930 and notes Archer's graduation from the Montreal High School for Girls. The McGill University transcript records the conferring of the Diploma of Licentiate in Pianoforte in May 1934 and of the Degree of Bachelor of Music in May 1936. It also notes the awarding of scholarships for post-graduate study in composition in 1936-37, 1938-39, 1939-40, and 1940-41, a series of awards that made possible an extended period of intense activity under the guidance of the Dean of the Faculty of Music at McGill, Douglas Clarke. Archer's student years came to an end in mid-1943, shortly after her thirtieth birthday, with her appointment to the faculty of McGill University. ${ }^{1}$

1 While Archer's name first appears in the list of faculty members in the McGill Calendar for 1944-45, there seems little doubt that she was appointed for 1943-44: university calendars are typically issued long in advance of the session to which they refer, with the result that they normally list instructors on staff in the previous year. This circumstance is explicitly acknowledged in the McGill Calendar for 1946-47, in which the faculty list is labelled "Session 1945-46." But, the Calendar aside, Archer's lecture 
The major objectives of this study, then, are to identify the works that Archer wrote prior to her appointment at McGill and to determine the date of completion for each one. In addition, the catalogue entries provide, for each work, the medium of performance, a list of movements, and the source of any text. They identify the most readily available score, whether a publication, a Canadian Music Centre reproduction, or an autograph manuscript, and note any publicly accessible recordings. Finally, they include information on first and early performances, if this presented itself in the sources consulted.

The catalogue was compiled principally from scores and includes only works for which scores were located. Room would have been made for lost works, had reliable evidence of their existence presented itself, and with this in mind several early lists were reviewed, compiled by Archer and others between 1940 and 1960, as well as all of the press clippings and programs in Archer's own files and those of the Canadian Music Centre. But with one exception, it proved possible to associate each work described in those sources with an extant score. (For the exception, see the unnumbered entry for the Theme and Variations for String Quartet, between works 60 and 61 in the catalogue of compositions.)

Only completed compositions are included. Compositions were considered to be complete if they exist as published works, as works copied onto transparencies, or as manuscripts that present a continuous, legible, and largely unambiguous text. Works that did not proceed beyond the draft stage or that remain as unfinished projects were excluded. (A single exception was made to describe an incomplete composition that has appeared on a published list of Archer's works; see the unnumbered entry for the Scherzo for String Quartet, between works 28.1 and 29.)

Finally, only completed compositions are included. Writings that, it seems, Archer considered to be exercises or mere diversions were excluded. On the other hand, in addition to original compositions, the catalogue includes several arrangements of works by other composers. And no attempt was made to distinguish juvenilia from more mature works; the objective was to include all completed compositions.

\section{Sources and Methods ${ }^{2}$}

As noted above, one of the objectives of this study is to establish the date of completion of each composition, to make it possible to present a catalogue that

notes for the second year Mus. Bac. counterpoint course are still extant (A 18.80), including the examinations she set, a series that begins with the 1943-44 session.

2 The writer wishes to acknowledge with thanks the assistance of staff members of the libraries in which source materials were consulted, in particular Appolonia Steele, Librarian, Special Collections, University of Calgary Library; John Reid, Director, Prairie Region, Canadian Music Centre, Calgary; and Mark Hand, National Librarian, Canadian Music Centre, Toronto. Thanks are also due to Allan Bell, Department of Music, University of Calgary, who loaned a file of biographical materials on Archer and provided a copy of a list of her compositions compiled in 1985 by the late George Proctor; and to Gertrude Olford, who investigated several questions in Montreal in the fall of 1994, in the Archives and Libraries of McGill University and elsewhere. A particular debt of gratitude is owed to Violet Archer herself, who has patiently responded to questions over a period of several years and permitted the writer the unrestricted access to her papers and manuscripts that has made this study possible. 
is chronologically arranged. The following paragraphs are organized as a discussion of the methods employed to assign those dates. In the course of that discussion, they also detail the sources consulted to identify the works in the first place and to supply the other information in the catalogue entries.

In many cases it was possible to determine a date of completion precisely, while in others a range of possibilities was the best that could be done. In the catalogue entries, the date or range is stated after the title, and justified in the notes at the end, based on one or more of the considerations discussed below.

\section{Dated Scores}

The principal source of information was the scores of the compositions. The following materials were reviewed:

(1) Published and unpublished scores in the libraries of the Canadian Music Centre in Calgary and Toronto and in the University of Alberta Library.

(2) The Violet Archer Fonds, accession 478/90.18 in Special Collections, University of Calgary Library, consisting principally of autograph manuscripts, with a few scores reproduced from transparencies. These materials are cited by the letter $C$ and the inventory number assigned by the Library (e.g., C 1.10).

(3) Materials in Archer's possession, much the largest of the three groups, including manuscripts (sketches, drafts, finished copies), transparencies and reproductions, and publications. An inventory of these materials was prepared by the present writer for use in this study; the materials are cited by the letter $A$ and the number assigned in that inventory (e.g., A 4.69).

Archer normally drafts a work in pencil and then prepares from the draft a continuous legible pencil score, which represents the completed composition. Since 1972, scores and parts for use or distribution have been written by copyists, working from the holograph pencil scores. But before that date, Archer usually did this work herself, writing on transparencies from about 1946 onwards and in ink on paper before that date. It seems to have been her normal practice to prepare such a final copy as soon as a work was completed. During the period of this study, additional copies were prepared by hand as required, so that two or more holograph ink scores may exist for a particular composition.

Orchestral compositions Archer normally writes first as short scores on two staves. Beginning with Britannia: A Joyful Overture, completed in February 1941, these short scores are, as one might expect, drafts in pencil. But prior to 1941 , they are invariably ink fair copies; pencil drafts no doubt existed, but were apparently not retained. Nevertheless, they do seem to represent a stage in the process of composition rather than a keyboard arrangement prepared after the work was completed: the ink short score (A 4.24) of the Poem for Orchestra, for example, although it is actually captioned "Pianoforte arrangement," carries a pencil note in Archer's handwriting, "I am orchestrating this at present." Archer recalls that her mentor, Douglas Clarke, preferred to see completed projects, rather than works in progress. Possibly she prepared the ink short scores for him to review before she began the orchestration. They cease to be a 
feature of the sources shortly before the end of her period of study with Clarke, 1940-41 being her last year on graduate scholarship.

Dates appear on many of Archer's scores. Unless there is evidence to the contrary, it has been assumed that these refer to the date of completion of the composition rather than to the date of writing of the score. This does appear to have been her practice almost invariably. There are, for example, three ink scores of the Variations on a French-Canadian Folk Song for piano (entry 21 in the catalogue). It is unlikely that these were all written at the same time, but they are all dated 29 October 1937. Even the scores of arrangements or new versions sometimes carry the original date of completion. The scores of the two string orchestra versions of the Variations on an Original Theme (entries 20.1 and 20.2 in the catalogue) are, like the score of the original orchestral version (entry 20), both dated September 1937, although other evidence suggests that they were written in the summer of 1938 and May 1939 respectively.

Most reliable are the dates on completed pencil manuscripts, as these were almost certainly supplied as the work was being done. But, since it seems that Archer normally prepared an ink copy of a work as soon as she finished composing, dates on ink scores, provided there is only a single copy, may be taken to be equally reliable. However, when there are two or more ink scores, it is likely that the duplicate copies were written some months or even years after the work was completed. The dates that appear on these scores are therefore open to some question, as they may have been supplied from recollection at the time the score was written.

Occasionally a single manuscript contains material relating to two works, typically a portion of an ink score of one, abandoned because of a mistake, and a pencil draft of another. Even though the manuscript may not be dated, such occurrences suggest the order in which the two works were written.

\section{Types of Paper}

During the period of this study, datable occurrences of a particular type of paper amongst Archer's manuscripts group themselves chronologically with remarkable consistency. It seems that she purchased manuscript paper in batches and used each batch completely before buying more. Successive batches can often be distinguished because they are produced by different companies, but even when two batches come from the same firm, differences (more or less subtle) in the printing make differentiation possible. In fact, the situation is slightly more complex. In the first place, there are two streams, one mostly of 12-stave papers, and another of orchestral papers of 18, 20, or 24 staves. And there are occasional instances in which small quantities of paper seem to have been retained and used several months after the main supply was depleted.

But the pattern is nevertheless so consistent that it seemed useful to compile a catalogue of types of paper and assign a date range to each one, so that the information could be used, along with other evidence, in assigning a date of writing to undated manuscripts. This catalogue of paper types precedes the catalogue of compositions. Papers are presented in chronological order of their first use; each entry includes a reference number, the range of dates during which 
the paper is thought to have been in use, a description of the paper, and a note presenting the evidence supporting the date range. In dating paper, it is necessary to bear in mind that dates written on scores are normally dates of composition, not of writing. Similarly, in dating compositions, date ranges assigned on the basis of the type of paper refer to the writing of the score and not to the composition of the work. As a practical matter, however, there are two types of manuscript over which caution must be exercised: duplicate copies of ink scores, and performance parts; these may have been written long after the works were composed. For pencil scores and single copies of ink scores, the date of composition and the date of writing can normally be assumed to be the same.

\section{Archer's Lists of Her Compositions}

In Archer's files are several lists of her compositions that she herself prepared. Although the lists are undated, it is possible to determine the dates of compilation with considerable certainty, since most of the works appearing on them can be dated reliably from independent sources.

1940 Compiled about July 1940. Consists of three pages, two typewritten, and one handwritten; most of the handwritten material also appears on the typewritten list, which breaks off incomplete. A classified list, giving title and medium of performance. Works performed up to the time of compilation are marked, but details are not given.

1952 Compiled after May and before November 1952. Originally consisted of eight typewritten numbered pages, of which only the last two have been located. A classified list, giving title and medium of performance, and, in the case of works performed, providing dates and identifying performers.

1957 Compiled after September 1956 and before June 1957. A classified list on two typewritten pages, providing title, medium of performance, and, in the case of published works, the name of the publisher. Contains several handwritten additions, some to correct oversights and others to update the list. Some of the handwritten entries for new compositions are dated.

1959 Compiled in April or May 1959, from the 1957 list and its handwritten additions. A classified list on five typewritten pages, providing, in addition to title and medium of performance, date of composition, duration, and, where applicable, publisher and record label. A few handwritten additions update the list.

1960 Compiled after January and before July 1960. A three-page typewritten list, providing all of the information on the 1959 list and incorporating its handwritten additions. Works are arranged chronologically within each medium-of-performance class. Two copies of this list were located, one of which is updated by several dated handwritten additions. 
These lists are most useful for dating works written around the time of their compilation. The compilation date of each list serves as a terminus ad quem for the composition of the works appearing on it and a terminus a quo for handwritten additions. And where one list succeeds another over a relatively short time span, the compilation dates define the range of possible composition dates for works appearing only on the second list. But for the purpose of this study of early compositions, the lists are valuable principally as evidence of the existence of works. The dates of composition on the 1959 and 1960 lists have proven to be reliable when they are associated with the handwritten additions or with works composed shortly before the lists were compiled. But those associated with works written in the 1930s and 1940s must be regarded as approximations.

The 1960 list has essentially become the public record of Archer's output up to the time of its compilation. Archer's files also include a four-page typewritten document headed "Canadian Composers - 21," one of a series of articles compiled by the International Service of the CBC, apparently for internal use. It consists of a biographical article by V. I. Rajewski dated 28 November 1961, with a list of works appended. The list provides just title, medium of performance, and date of composition, but corresponds in wording and content to Archer's 1960 list with its handwritten additions. A revised version of the article, together with the list of works, was published in the CBC's Thirty-four Biographies of Canadian Composers in 1964. The list of works, as published, omits four of the entries on the 1961 list and adds four works written in 1962 and 1963. But it is otherwise identical in content, and virtually identical in wording. Later published lists, of course, make revisions and provide additional information, but the list published in 1964 is nevertheless the basis for those published in Dictionary of Canadian Composers, ${ }^{3}$ Compositeurs canadiens contemporains, ${ }^{4}$ and both editions of the Encyclopedia of Music in Canada. ${ }^{5}$

\section{Other Lists}

Four early published lists provide valuable evidence of the existence of works, as well as a terminus ad quem for the composition of the works they cite. Of these, only Helmut Kallmann's has as its objective the presentation of a complete catalogue; the list issued by the Canadian Federation of Music Teachers Associations is selective, and the others are merely reports of interviews in which recently-completed compositions were mentioned.

Goltman, Frances. "Musical Sharps Flats and Naturals." The Monitor (Montreal), ca. 23 August $1945 .{ }^{6}$ Mentions ten of Archer's "more important" works.

3 Dictionary of Canadian Composers, ed. Keith Macmillan and John Beckwith (Toronto: Oxford University Press, 1975), 14-17.

4 Compositeurs canadiens contemporains, édition française dirigée par Louise Laplante; traduction de Véronique Robert (Montreal: Presses de 1'Université du Québec, 1977), 21-25.

5 Encyclopedia of Music in Canada, ed. Helmut Kallmann, Gilles Potvin, and Kenneth Winters (Toronto: University of Toronto Press, 1981), 28; 2nd ed. (1992), 36-37.

6It has not been possible to obtain a precise citation. The Monitor has apparently not been microfilmed, and the publisher does not have 1945 issues on file. But it is clear from other topics discussed 
A List of Canadian Music. Toronto: published for the Canadian Federation of Music Teachers Associations by the Oxford University Press, 1946. Classified by medium of performance. Includes entries for twenty-two works by Archer.

Wilson, Winifred E. "Canada's Coming Woman Composer." Canadian Home Journal 43, no. 6 (October 1946): 2, 28. Mentions twenty-two works, including most of those written in the preceding five years.

Kallmann, Helmut. Catalogue of Canadian Composers. Revised and enlarged edition. Toronto: Canadian Broadcasting Corporation, 1952. A classified list, providing title and medium of performance.

Two serially-published lists provide an on-going record of completed compositions, along with other data. They relate to a period considerably later than that covered by the present study but have been consulted for information on revised versions and performances.

Canadian Music Centre Accession Lists: A serial record of additions to the CMC library of scores, published several times per year in MusiCanada (covering accessions from 1 January 1967 through 30 November 1970), The Music Scene (1 December 1970 through 14 April 1976), and MusiCanada (15 April 1976 through 31 December 1981), and issued annually from 1982 by the Centre itself.

"American Composer Update" and its predecessors, appearing annually in the second issue of each volume of Pan Pipes of Sigma Alpha Iota. The column documents premières and other performances, publications, and recordings for the previous year, based on reports submitted annually by the composers themselves. The January 1953 issue $(45$, no. 2) was the first to report on Archer's activities. The information is generally reliable, having been compiled within a few months of the events chronicled, but as some inaccuracies were noted, it has not been accepted without an attempt at independent verification.

Finally, two researched lists were consulted. Information drawn from these two lists is acknowledged as it is presented in the catalogue of compositions.

Proctor, George. "Violet Archer: Chronological List of Works (Complete)." This unpublished list is dated 12 November 1985. A copy was made available through the kindness of Allan Bell, of the Department of Music, University of Calgary.

Hartig, Linda. Violet Archer: A Bio-Bibliography. Bio-Bibliographies in Music, no. 41. New York: Greenwood Press, 1991. This volume contains the most extensive list of Archer's works published to date. 


\section{Archer's Name and Address}

An article on page 24 of The Montreal Daily Star for 22 June 1940 announced that "Violet Balestreri, Montreal organist and composer, wishes it to be known that she will in future be known as Violet B. Archer." The translation of their surname was a family decision, Archer says, taken in response to the entry of Italy into the war on 10 June.

The family lived successively at three addresses in Montreal in the 1930s and 1940s. The telephone directory dated January 1933 lists them at 2163 Tupper Street; the one dated September 1933 lists a new address, 1045 Atwater Avenue. Revisions to the Yellow Pages of these two editions were required by November 1932 and May 1933 respectively. The books present no information about the closing dates for changes to the alphabetical listings, which may have been later than the deadlines for the Yellow Pages. One can only conclude that the move to 1045 Atwater Avenue took place between November 1932 and September 1933. However, Archer's files include a university notebook whose cover bears the Tupper street address and the date April 1933. It seems likely therefore, that this move took place between April and September 1933.

The Archers moved again between 2 September 1941 and 8 June 1942. These are the closing dates for changes to the October 1941 and July 1942 issues of the Montreal telephone directory; the latter contains the first occurrence of the third address, 3446 Décarie Boulevard.

Archer's address and the form of her name are useful in dating a limited number of manuscripts written near the times that the changes occurred. The evidence has been used cautiously, however; it is possible for a name or address to be added to a manuscript long after the date of writing, or for a manuscript copy of a work to be prepared long after it was composed.

\section{Programs, Press Clippings, and Correspondence}

Biographical files at the Canadian Music Centre Libraries in Calgary and Toronto were reviewed, as well as a file kindly loaned by Allan Bell, and Archer's own extensive files of programs and press clippings. This material was valuable chiefly in establishing the details of performances. Programs were the main source, but information from concert reviews was preferred above all, since these occasionally report late changes in repertoire or personnel which do not appear in the printed programs. Date and source information noted on the clippings was verified in the University of Alberta Library's microfilms of the newspapers concerned. These films were also searched in a number of cases in which press reports seemed likely to exist and did not appear in the files.

Information on first and early performances is recorded in the catalogue entries whenever it presented itself in the sources consulted. However, for the purpose of this study, performance information was valued not so much for itself as for the evidence it provides regarding the date of completion of a work, so it was not sought when it was not required for that purpose.

Letters relating to commissions, copyright permissions for texts, preparation of performance materials, and the like have an obvious value in establishing 
dates of composition for the works with which they deal, as do references of a more casual nature. This was not a major source for the dating of Archer's early compositions, but correspondence was studied when it was encountered in the course of reviewing her files of programs and press clippings; it occasionally supplied useful details.

\section{Library Catalogues}

The entries for Archer's works in the catalogues of the libraries consulted were reviewed, including the published and on-site catalogues of the Canadian Music Centre libraries, and the catalogue of the University of Alberta Library. Particularly valuable was the catalogue of the CMC sound recordings collection, which provides information on the provenance of unpublished sound recordings that is not present on the recordings themselves.

\section{Archer's Recollections}

Violet Archer has an amazingly clear recollection of the substance of events that occurred in the course of her long career, and she was generous in taking time to respond to questions. The writer took responsibility for establishing or verifying the dates of events, but relied more heavily on Archer's accounts of their order and relationships. This indebtedness is acknowledged in the notes to the catalogue entries; see for example, those on paper type 131 and work 34.

\section{User's Guide}

Entries in the catalogue of compositions are organized according to the following format and provide as much of the information as is applicable and available.

Reference number Title. Date of composition.

[For each movement] Title: Tempo indication, "First line of text" (medium of performance). Date of composition.

Genre and medium of performance, including, when appropriate, choir voicing, orchestral instrumentation, and vocal range / Relationship to other works / Source of text and melody / Availability / First (or earliest known) performance: place, date (performers), occasion / Dedication / Recordings: identification (performers) (duration) / Entry number in Hartig.

Notes.

The date of composition is the date on which the work was completed. In some cases it has been necessary to specify a range of possible dates. In the case of a few works whose movements were written at different times, the date following the title is the date of completion of the entire work; the date of completion of each movement appears in the list of movements.

Entries in the catalogue are arranged and numbered chronologically by the date of completion. An exception is made for works that exist in two or more 
versions or that were revised several years after completion; all versions are entered together and assigned subdivisions of the same reference number. If the later versions or revisions were completed before the closing date of this study, brief entries appear later in the catalogue, at the appropriate point in the chronological sequence, with a reference to the number of the complete entry.

In the list of movements, only the tempo indication appearing at the beginning of each movement is given. This is not always indicative of the character of the movement, but the listing of additional tempo indications was not found to be practical. Information on medium of performance, as well as date of composition, is included in the list of movements if it is not the same for all.

In the statement of medium of performance, voicing of choral works is indicated by providing a letter for each part that maintains an independent existence throughout the work or movement. For example, SATB (S divisi) indicates division of the soprano part for some of the work but not all; SSATB indicates a work in five real parts throughout. Divisi passages are noted except when the division of the part is limited to final chords of cadences.

Orchestral instrumentation is indicated by listing the number of each of the standard instruments required, in score order, in the widely-used manner. Other instruments are named, following a plus sign if an additional player is required, and enclosed in parentheses if not:

2+pic.2.2.2 $\backslash 4.3 .3 .1 \backslash$ timp $\backslash$ strings [ 2 flutes and piccolo, 3 players in all]

2(pic).2.2.2 44.3.3.1 \timp $\backslash$ strings [2 flute players, one of whom also plays piccolo] Percussion instruments are listed, but no attempt is made to specify the number of players required. The following abbreviations are used:

$\begin{array}{ll}\text { pic } & \text { piccolo } \\ \text { engh } & \text { English horn } \\ \text { bcl } & \text { bass clarinet } \\ \text { timp } & \text { timpani }\end{array}$

Vocal ranges are given for works for solo voice, using the following system:

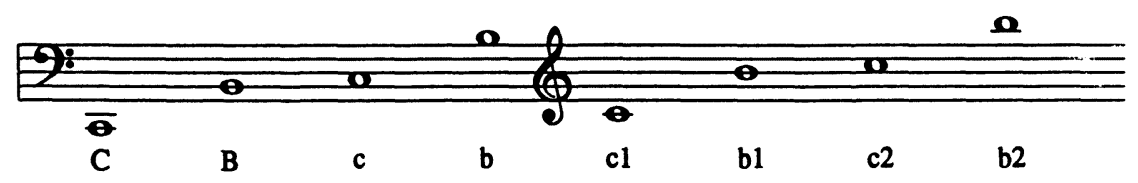

Availability is indicated by identifying the most readily accessible score. A publication is cited if there is one, or a manuscript reproduction available from the Canadian Music Centre, by giving the imprint information (place of publication: publisher, date of publication) in the former case, and the letters $C M C$ in the latter. In the case of unpublished works not at the Canadian Music Centre, a specific manuscript copy is cited. When several copies exist, the citation identifies the one considered to present most clearly the composer's final version. The manuscripts are located either with the Violet Archer Fonds, accession 478/90.18 in Special Collections, University of Calgary Library, or amongst materials in Archer's possession. Those in Calgary are cited by the 
letter $C$ followed by the inventory number assigned by the Library (e.g., C 1.10), and those in Archer's collection by the letter $A$ followed by the number assigned in the writer's inventory of her scores (e.g., A 4.69). The word "manuscript" is abbreviated $\mathrm{Ms}$ in this context and unless otherwise specified always refers to a Violet Archer autograph.

The earliest known performance is listed whenever this information presented itself in the sources consulted for this study. The performance is designated as the première when it is so described in a primary source, normally the program of the performance, an announcement or review in the press, or the score itself.

Sound recordings cited in the catalogue entries are all unpublished recordings accessible in the libraries of the Canadian Music Centre or in the Music Library at the University of Alberta. No commercially-released sound recordings of the works catalogued in this study have been identified.

Each entry concludes with a reference to the catalogue of Archer's compositions, which appears in Linda Hartig, Violet Archer: A Bio-Bibliography, Bio-Bibliographies in Music, no. 41 (New York: Greenwood Press, 1991). For works which appear in that catalogue, Hartig's reference number is given.

The notes at the end of each entry are primarily concerned with documenting dates of composition and details of performances. For information that can be conclusively determined, only the source considered to be the most reliable is cited. But all available evidence is presented in the case of details that are the subject of conjecture. For ease of reference, titles of Archer's works are followed immediately by their entry number in the catalogue of compositions. Manuscripts at the University of Calgary or in Archer's possession are cited by the letter $C$ or $A$ and an inventory number, as explained above. The terms "ink score," "pencil score," "pencil draft," and "pencil sketch" all refer to autograph manuscripts; copyists' manuscripts are described as such. Paper types are cited by the numbers assigned to them in the catalogue of paper types. The number is usually followed by a statement of the period of time during which the paper is thought to have been in use, but no justification of this statement is provided; the appropriate entry in the catalogue of paper types must be consulted for that information. Archer's own lists of her compositions are cited by the phrase "Archer's [date] list," the date being the year of compilation, as designated in the section titled "Archer's Lists of Her Compositions" above.

Notes relating to performances often consist of the single word "Program." This indicates that the printed program supplied all of the data; if the performance is designated as a première, the program provided that information as well. When other sources were consulted, a full explanation is provided.

\section{Catalogue of Paper Types}

The catalogue that follows includes all of the manuscript papers used by Violet Archer during the period of this study. The papers are listed in chronological order of their first use, and each is assigned a number by which it is cited in the catalogue of compositions. The entry for each paper provides a description 
and states the period of time during which it is thought to have been in use; notes at the end of the entry present the supporting evidence. The conventions employed in these notes are the same ones used in the notes in the catalogue of compositions; see the last portion of the "User's Guide" for more information.

\section{October 1932?-Summer 1933?}

No maker's name. 12-stave folio, with text ("Conservatory Brand Made and Printed in England") at the top of the first recto.

There are just two occurrences. One consists of a booklet of six folios (A 3.39), containing counterpoint exercises dated 4 October 1932 through 28 March 1933. The other is a booklet of three folios (A 1.35), with harmony exercises and ink scores of works 1 and 2 . It is undated, but the address "2163 Tupper Street" appears on p. 1, indicating that it was written before September 1933.

\section{June 1935?}

No maker's name. 10-stave leaf torn from a pad along a perforation, printed only on one side, with no identifying marks. Paper size is $21.2 \mathrm{~cm} \mathrm{x} 25.8 \mathrm{~cm}$; printed area is $21.2 \mathrm{~cm} \mathrm{x} 21.7 \mathrm{~cm}$ (no side margin).

See notes on Jig for Orchestra (3).

\section{Summer 1935?}

No maker's name. 14-stave folio with no identifying marks. Page size is 23.75 $\mathrm{cm} \times 29.75 \mathrm{~cm}$; printed area is $19.1 \mathrm{~cm} \times 25.35 \mathrm{~cm}$.

The only datable occurrence is in the ink score (A 1.31.1) of the Intermezzo for Orchestra (6). This score must have been written after August 1935, since it bears that date of composition, and before the première on 28 May 1936, since it was signed and dated by the conductor on that occasion, Reginald de Haviland Tupper. The other scores (A 1.32, A 1.34) in which this paper occurs may have been written earlier (see notes on works 4 and 5 ).

\section{July 1935?-October 1936}

North American Printing Co. Ltd. 12-stave folio, "N.A.P. Co. Ltd. - 10," with logo and text on the fold at the foot of both sides of the sheet. Printed area of each page is $19.3 \mathrm{~cm} \mathrm{x} 27.75 \mathrm{~cm}$.

More than one hundred folios were used over a period of about fifteen months beginning in the summer of 1935. The earliest dated occurrence is in the ink short score (A 1.31.2) of the Intermezzo for Orchestra (6), which is dated August 1935. Since at that time Archer normally prepared an ink short score before beginning to orchestrate a work, there is every reason to suppose that this score was written in August 1935 , during the composition process, rather than later. In fact, it seems likely that the paper was purchased somewhat earlier, to prepare a set of parts (A 3.59, A 13.81) for the Three Russian Folk Dances (4) (see notes on that work). Another eight dated occurrences range from 18 February 1936, in an incomplete ink score (A 3.25.3) of the Fugue on Given Subject (7), through April 1936, in the ink short score (A 1.25.1) and full score (A 14.20) of the Miniature Suite (10). The supply of type 104 appears to have run out in the course of preparing the parts (A 3.22) for the Scherzo and Andante (11), four of which were written on type 104, and the remainder-the large majority-on the principal successor paper, type 110 . These two movements were composed in August 1936 and July 1936 respectively and performed by the McGill Orchestra on 17 December 1936. The parts may therefore have been written early in the fall of 1936, a date consistent with that of the first dated occurrence of type 110, September 1936. A single folio of type 104 was used in the score (C 1.8.1) of the Fugue (13), dated October 1936. 


\section{December 1935-March 1936}

North American Printing Co. Ltd. 12-stave spiral-bound notebook, with logo and text at the foot of each page. Text reads "N,.P. [sic] Co. Ltd. -10" on rectos, and "N.A.P. Co. Ltd - 10" on versos.

The only occurrence is a notebook (A 3.25.1) containing counterpoint exercises whose dates range from December 1935 through March 1936.

\section{Summer 1936?}

North American Printing Co. Ltd. 12-stave folio, "N.A.P. Co. Ltd.-10," with logo and text on the fold at the foot of both sides of the sheet. Printed area of each page is $13.7 \mathrm{~cm} \times 22.95 \mathrm{~cm}$.

Occurs along with type 104 paper in the ink short score (A 1.24) of the Scherzo and Andante (11), of which the full scores (A 1.33.1, A 1.33.2) are dated August 1936 and July 1936 respectively. Sheets of type 106 are laid into the type 105 notebook (A 3.25.1) containing counterpoint exercises whose dates range from December 1935 to March 1936. In all, fewer than ten folios have been located.

\section{April 1936}

No maker's name. 10-stave leaf torn from a pad along a rough perforation, printed only on one side, with no identifying marks. Paper size is $21.35 \mathrm{~cm} \mathrm{x}$ $25.6 \mathrm{~cm}$; printed area is $21.35 \mathrm{~cm} \times 21.9 \mathrm{~cm}$.

Occurs only in the pencil full score (A 1.25.2) of the Miniature Suite (10), of which both the ink short score (A 1.25.1) and ink full score (A 14.20) are dated April 1936.

\section{January 1936?}

Albert Pelletier. 12-stave folio, "No 3 - 12," "2162 rue Mousseau, Montreal," with logo and text at the foot of each recto.

Occurs only in the Oboe II part for the Intermezzo for Orchestra (6), composed in August 1935 and performed by the McGill Orchestra on 28 May 1936.

\section{July 1936-February 1937}

Belwin. 12-stave leaf, "Belwin Pad No. 3 A - 12 lines Wide Spacing," printed both sides, with text at the foot of each recto.

Used for the ink full scores (A 1.33.1 and A 1.33.2) of the Scherzo and Andante (11), which are dated August 1936 and July 1936 respectively. These dates are assumed to be dates of composition, but it is likely that the ink full scores were prepared almost immediately, since the work was performed by the McGill Orchestra on 17 December 1936, and the parts appear to have been written before the end of September (see note on type 104 paper). The paper was used again in two ink short scores of Choruses from "The Bacchae" (Euripides) (15), one (A 3.64) clearly a revision of the other (A 3.63). The first is dated January 1937, and it seems likely that the second was written soon after, as it is followed by a further revised ink short score (A 3.50), a pencil full score (C 1.12), and an ink full score (C 1.13) that is dated April 1937.

\section{September 1936-March 1938}

Albert Pelletier. 12-stave folio, "No. 3A-12," "2162 Mousseau, Montreal," with logo and text at the foot of each recto.

Available in quantity for eighteen months beginning in September 1936, the successor to type 104. The paper was probably purchased to prepare the parts for the Scherzo and Andante (11), which must have been copied early that fall (see note on type 104 paper). It is used in two ink scores (C 1.9.1, C 1.9.2) of Song ("I dare not ask a kiss") (12), dated September 1936 and October 1936 respectively; since the two 
scores present identical texts (the second one eliminates a page turn), at least the second date appears to be the date of writing, rather than of composition. Ten dated occurrences of type 110 document its subsequent use through 1937, ending with the ink score (C 1.22.3) of a group of three "fun pieces" for piano dated 20 January 1938. The six scores (C 1.24, A 4.26, A 17.83, C 1.6, A 4.6, and A 3.40) that Archer entered in the composition classes of the Quebec Musical Competition Festival in March 1938 provide further evidence of the use of type 110 paper around that time. They are identifiable by the class and competitor numbers that they carry and, with the exception of one orchestral score, are duplicates apparently prepared for the purpose. Two of the works are orchestral scores on type 111 paper, but the other four are all written on type 110. The supply of 110 seems to have run out in the course of preparing the parts (A 1.40) for the orchestral version of the Variations on a French-Canadian Folk Song (21.1), as the woodwinds are on type 110, and the remainder on a successor paper, type 113. The ink full score (A 14.13) of this work is dated March 1938, and the parts could have been prepared at any time after that date. But as other successor papers were already in use in an ink short score dated 19 March 1938 (A 18.66, Poem for Orchestra (24), on type 114) and in the ink score of a short "fun piece" for piano dated 4 April 1938 (C 1.22.2, on type 115), it seems likely that the parts were written, and the supply of type 110 depleted, by the end of March.

(An ink score (A 13.84) of the Mass in the Dorian Mode (9) is written on type 110 paper, and dated April 1936. It is possible that the paper was purchased to prepare that score. But it is a fair copy, incorporating pencil revisions written on the March 1936 ink score (A 13.64), and could therefore have been written well after the date of composition, possibly even late in 1937 when a score of the "Agnus Dei" (C 1.6) was being prepared as a Festival entry. As no other uses of the paper before September 1936 can be substantiated, and other equivalent papers (types 104, 106, 109) were in use through that summer, it seems prudent for purposes of dating undated works written on type 110 to assume that it was not available until September.)

\section{April 1937-March 1938}

G. Schirmer. 24-stave folio, "Royal Brand No. 61 - 24 Staves," with logo and text at the foot of each recto.

Of four dated occurrences, the two earliest are ink scores (C 1.13, A 17.83) of Choruses from "The Bacchae" (Euripides) (15), both dated April 1937. The first of these may be assumed to be the fair copy written at the time of composition. But the second may have been written several months later, as it bears the marks of an entry in the Quebec Musical Competition Festival held in March 1938. The third and fourth occurrences are in the ink score (A 3.40) of the first version (for full orchestra) of the Variations on an Original Theme (20), dated September 1937, and in the ink score (A 14.13) of the orchestral version of the Variations on a French-Canadian Folk Song (21.1), dated March 1938. Other occurrences fit comfortably into this time span, being pencil scores (C 1.12, C 1.14.1, C 1.10.1) of the same three works, and a pencil score (C 1.28) of the Rhapsody for Orchestra (18), whose ink short score (C 1.16) is dated August 1937. A single folio occurs, along with successor papers, in the pencil score (A 2.22) of the Capriccio for Tympani and Orchestra, of which the ink score is dated April 1939.

\section{February?-June 1937}

No maker's name. 12-stave leaf, with no identifying marks. Page size 24.45 $\mathrm{cm} \times 31.4 \mathrm{~cm}$; printed area $19.85 \mathrm{~cm} \times 26.25 \mathrm{~cm}$.

Just six leaves have been located. There is one dated occurrence, a counterpoint exercise for a student, headed "Mrs. Brophy, June '37." Two more leaves are associated with a draft (A 1.16) of an incomplete setting of the St. Matthew Passion written on nine leaves of type 109 paper (July 1936-February 1937); one contains revisions to the verso of leaf 4 of the draft; the other contains a continuation of the verso of leaf 9 . This may have been written during Lent 1937.

\section{March 1938-December 1939}

No maker's name. 12-stave folio, with text ("The Conservatory Brand Made and Printed in England") at the top of the first recto.

One of three successors to type 110 , this paper was used exclusively to write orchestral parts. Sixty-six folios were used in the parts (A 1.40) for the orchestral version of the Variations on a French-Canadian 
Folk Song (21.1), and another eleven folios in sets of parts for three other works. Thus it appears that the paper was purchased to complete the parts for the Variations, which were begun on type 110 paper and probably written in March 1938 (see note on type 110 paper), and that the folios which remained were used later to write first copies of the string parts for the other three works. In two of these three cases, the remaining parts were written on type 115 paper; since the works were both performed on 10 January 1939 , the sets were probably complete by the end of August 1938. These are the first string orchestra version of the Variations on an Original Theme (20.1) (the parts (A 3.21) include one copy each of Violin I and Cello on type 113), and the string orchestra arrangement of Maurice Greene's Suite in G Major (14) (the parts (A 4.5) include one copy each of Violin I, Violin II, and Cello on type 113). The third set of parts, however, prepared for a performance by string orchestra of the last two movements of the String Quartet No. 1 (28.1) ("Theme and Variations" and "Rondo"), must have been written about a year later: the Quartet was completed in July 1939, and the performance took place on 7 March 1940. The parts (A 1.6) include two copies of Violin I and one copy of Violin II on type 113, representing a total of six folios which must have escaped being used until late in 1939. The parts were completed on type 123 paper, which occurs nowhere else.

\section{March 1938-April 1939}

Albert Pelletier. 12-stave folio, "No. 3A-12," "2162 Mousseau, Montreal," with logo and text at the foot of each recto. Supplied in a book of twelve folios stapled into a yellow cardboard cover labelled "Students Music Blank Book No. L 3-12, 48 pages."

This is the same paper as type 110, but distinguished from it by the presence of staple marks on the fold. It is one of three successors to type 110 paper. While type 113 was used exclusively, and type 115 almost exclusively, for the copying of orchestral parts, type 114 was used for new compositions. The earliest dated occurrence is in the ink short score (A 18.66) of the Poem for Orchestra (24), dated 19 March 1938, on two and one-half folios still stapled into the original cover. Ten dated occurrences document subsequent use of the paper, ending with the ink scores (A 13.79, A 13.73) of the first and third movements of the Six Pieces for Piano and Tympani (29), both dated March 1939. Two occurrences may be slightly later. One of these, the pencil score (C 1.19.10) of "Capriccio," the fourth of the Six Pieces, is undated, but the ink score (A 2.21) of the orchestral arrangement of the Capriccio (29.1) is dated April 1939; this may represent a date of composition. The other is a complete score (C 1.25) of the Six Pieces, copied in ink on ten folios of type 114 still stapled into the original cover. This would have been written after the composition of the individual movements, no earlier than March 1939, and possibly later, depending on the date of composition of the "Capriccio." (In fact, the score is dated January 1939, but this date must be inaccurate, no doubt a result of being added long after the score was prepared. For the date is written, not in the ink of the score, but in the same ink used to add the name "Violet B. Archer" on the cover, an addition which would not have been made before 22 June 1940.) It seems unlikely that type 114 was available after April 1939; a successor paper, type 121, was used already in the ink short score (A 1.4.3) of the third movement of the Symphonic Suite (32), which is dated April 1939.

\section{April-August 1938}

North American Printing Co. Ltd. 12-stave folio, "N.A.P. Co. Ltd. - 501," with logo and text on the fold at the foot of both sides of the sheet. Printed area $19.3 \mathrm{~cm} . \times 27.85 \mathrm{~cm}$.

One of three successors to type 110 paper, used principally for the copying of orchestral parts. As mentioned in the note on type 113 paper, type 115 seems to have been purchased to complete the sets of parts (A 3.21, A 4.5) for the second version of the Variations on an Original Theme (20.1), and for the string orchestra arrangement of Maurice Greene's Suite in G Major (14), tasks carried out between March and August 1938. Much the same period of use is suggested by dated occurrences of the paper, which range from 4 April 1938 on an ink score (C 1.22.2) of a short "fun piece" for piano to August 1938 on ink scores (A 13.70, A 4.34) of the sixth movement of the Six Pieces for Piano and Tympani (29), and of the piano piece called Midsummer Apathy (25). 


\section{August 1938?}

No maker's name. 12-stave folio, beige in color, with no identifying marks. Page size $23.15 \mathrm{~cm} \times 29.7 \mathrm{~cm}$; printed area $19.1 \mathrm{~cm} \times 25.75 \mathrm{~cm}$.

There are only two occurrences, three folios in an undated ink score (A 4.69) of the Prelude on "Aeterna Christi munera" (23), and three more in an ink short score (A 4.24), dated March 1938, of the Poem for Orchestra (24). Another ink copy of each of these scores exists, C 1.10 .2 of the Prelude, dated July 1938, and A 18.66 of the Poem, dated 19 March 1938. Comparison makes it clear that these are the originals, and those on type 116 paper the fair copies, prepared later. Thus A 4.69 was written in July 1938 or later, and A 4.24 sometime after 19 March 1938. In fact, the two scores were probably written at about the same time; 12-stave folios of types 113,114 , and 115 were all in active use in 1938 and 1939, and it is unlikely that three folios of type 116 would have sat unused for long. This writing would certainly have been done before April 1939, that is, before the preparation of the orchestral score (A 18.67) of the Poem (see note on type 117 paper), since a pencil note in Archer's handwriting on the first page of A 4.24 states, "I am orchestrating this at present." But it probably occurred much sooner: A 4.69 incorporates extensive revisions, which seem to have been worked out before the end of August 1938 (see note on the Prelude, work 23).

\section{August 1938?-April 1939}

G. Schirmer. 24-stave folio, "Imperial Brand No. 6-24 Staves," with logo and text at the foot of the first recto.

Only twelve folios of this paper have been located. Eleven of these are used in the pencil score (A 18.67) of the Poem for Orchestra (24), and the other, along with one folio of type 111 and four of type 119, in the pencil score (A 2.22) of the Capriccio for Tympani and Orchestra (29.1). Neither occurrence is dated, but the boundaries are set by the short score (A 18.66) of the Poem, dated 19 March 1938, and by one of the two ink scores (A 2.21) of the Capriccio, dated April 1939. It seems likely that the supply of type 111 was depleted in the preparation of the ink score (A 14.13) of the Variations on a French-Canadian Folk Song (21.1), which is dated March 1938, since no subsequent use of a quantity of this paper has been noted. A small quantity of type 117 seems then to have been purchased, probably after August 1938 (see note on type 116), to prepare the score of the Poem, and a much larger quantity of type 119 about April 1939 when paper was needed for the scores of the Capriccio. Single leftover folios of type 111 and 117 were used in the pencil score of the Capriccio, along with four folios of the new type 119; the ink scores were then written entirely on the new paper.

\section{September 1938-June 1939}

Albert Pelletier. 10-stave leaf, "No. T 2-10," printed only on one side, with logo and text at the foot of each leaf.

Thirty-three leaves have been located, all used for pencil sketches and drafts. None carry dates that appear to be original, but five of the seven occurrences are datable nevertheless. Seventeen leaves occur in drafts of the first (C 1.19.4), third (C 1.19.3), and fourth (C 1.19.5) movements of the first version of String Quartet No. 1 (28). Since the completed ink score (A 16.51.1) of the work is dated December 1938, the drafts probably date from the fall of that year. But work may have started somewhat sooner: the second movement is drafted on type 115 paper (April-August 1938). Another six leaves were used in an incomplete draft (C 1.19.1) of the fifth of the Six Pieces for Piano and Tympani (29), whose ink score (A 13.78) is dated February 1939. Finally, on another four leaves is written a set of parts (A 16.51.2) for the theme of the third movement of the second version of the String Quartet (28.1), of which the ink score (A 1.5) is dated July 1939.

\section{April 1939-December 1940}

Bosworth. 24-stave folio, "No 8. (24 Staves)," with logo and text at the foot of each recto.

As described in the note on type 117 paper, type 119 seems to have been purchased as a successor to types 111 and 117, to prepare the pencil (A 2.22) and ink (A 2.21) scores of the Capriccio for Tympani and Orchestra (29.1), the ink score of which is dated April 1939. Although more than 120 folios have been 
located, there are no other occurrences bearing dates that can be considered original. However, there are several datable occurrences, in the ink score (A 5.24) of the third movement of the Symphonic Suite (32), performed on 18 February 1940; in the pencil (A 14.12) and ink (A 18.49) scores of the complete Suite, the ink short scores (A 1.4) of which are dated April (movement 3), September (movement 4), and November (movement 1) 1939; and in the ink score (C 1.33) of the arrangement for women's chorus and orchestra of the first movement of Leaves of Grass (41.1), which was performed on 9 October 1940. Type 119 seems not to have been available in quantity after the end of 1940, as all of the orchestral scores (A 3.33, C 2.1, A 21.1) of Britannia: A Joyful Overture (45), completed in February 1941, are written on its successor, type 128. However, a single folio was used to draft an incomplete arrangement for cello and orchestra of the Fantasia Concertante (53), of which the pencil score (A 19.11) is dated July 1941.

\section{April-June 1939}

Albert Pelletier. 12-stave folio, "No. 5-12," with logo (12.5 mm high) and text at the foot of each recto. Gap between printed area and lower edge of paper is $8 \mathrm{~mm}$.

\section{$121 \quad$ April-June 1939}

Albert Pelletier. 12-stave folio, "No. 5-12," with logo (12.5 mm high) and text at the foot of each recto. Gap between printed area and lower edge of paper is $3 \mathrm{~mm}$.

\section{May-November 1939}

Albert Pelletier. 12-stave folio, "No. 5-12," with logo (12.5 mm high) and text at the foot of each recto. Gap between printed area and lower edge of paper is $9 \mathrm{~mm}$.

These three papers were purchased in the spring of 1939 as successors to type 114 . They have identical printing, and differ only in the vertical position of the printed material on the page. It is possible that they were purchased in a single batch, but they seem not to have come into use simultaneously, and it has therefore been assumed that they were purchased separately.

Two tasks that consumed a large quantity of these papers, although they are undated, can confidently be assigned to the second quarter of 1939. One is the preparation of the score (A 1.14) and parts (A 3.36; one double-bass part at C 1.15) for the third version of the Variations on an Original Theme (20.2). A fortuitous circumstance makes it possible to demonstrate that this took place before July 1939. An incomplete Violin I part (C 1.23.4) for the Variations, abandoned because of an error, or because enough copies had already been produced, was reused in a subsequent task, the revision of the String Quartet No. $l$ (28.1). The revision involved the composition of a new third movement, and a portion of this was sketched on the abandoned part. The completed score (A 1.5) of the revised version of the String Quartet is dated July 1939. The second task is the preparation of the parts (A 2.23) for the Capriccio for Tympani and Orchestra (29.1). This no doubt took place after the writing of the ink score (A 2.21), which is dated April 1939. It is highly probable that it took place before the preparation of the score and parts for the Variations. The parts for the Capriccio are written entirely on type 120 paper, requiring forty-two folios. Only three other folios have been located, and it seems reasonable to suppose that they are what remained when that job was done. Two of them were used in the parts for the Variations, and the third (A 16.51.2) to draft a new trio for the second movement of the String Quartet.

It seems likely, then, that type 120 was purchased in April 1939, and used immediately to write the parts for the Capriccio. Type 121 was purchased next, as indicated by its use in the ink short score (A 1.4.3) of the third movement of the Symphonic Suite (32), dated April 1939. The quantity purchased was very small; only seventeen folios have been located. So the preparation of the score and parts of the Variations, which required twenty-five folios, necessitated the purchase of type 122, probably in May. Five folios of type 121 were used in that task (along with eighteen of the new type 122 and two of type 120), and another four in a booklet (C 1.23) of sketches and drafts that seems to be related to the revision of the String Quartet. Several other occurrences of type 121 cannot be dated, but it seems likely that the supply was exhausted by the end of June, since it is only type 122 that is found in dated occurrences over 
the next several months, the ink score (A 1.5) of the String Quartet, dated July 1939, and the ink short scores (A 1.4) of the fourth and first movements of the Symphonic Suite, dated September and November 1939 respectively. The supply of type 122 seems to have run out in the course of preparing a set of parts (included in A 1.5) for the String Quartet, the Violin I part being written on type 122, and the rest on its successor, type 124. It is of course possible that these parts were written in July 1939, along with the score, but since no other use of type 124 can be substantiated before January 1940, it is more probable that they were written late in the year. A pencil score (A 3.3) of Prelude for Piano (35), dated March 1940, is written on two half-folios, one of type 121 and one of type 122 . These must be stray pieces saved for drafts; the ink score (A 2.46) of the piece is written on type 124, and there is no circumstance suggesting that either type 121 or 122 was available in quantity at that date.

\section{$123 \quad$ Fall 1939?}

Frederick Harris. 12-stave folio, with text ("Made in England for the Frederick Harris Co., Oakville, Ont.") at the foot of each page.

The only occurrence is in the parts (A 1.6) for the "Theme and variations" and "Rondo," the last two movements of the second version of the String Quartet No. 1 (28.1), which were performed by the McGill Conservatorium String Orchestra. These parts would have been written after the completion of the score (A 1.5), which is dated July 1939, and before the performance, which took place on 7 March 1940.

\section{December 1939-July 1940}

Albert Pelletier. 12-stave folio, "No. 5-12," with logo (6.5 mm high) and text at the foot of each page. Supplied in a book of twelve folios stapled into a yellow cardboard cover labelled "Students Music Blank Book No. L 3-12, 48 pages."

Available in quantity in the first half of 1940, a successor to type 122. The earliest dated use is in the ink score (A 4.73.1) of the Prelude on "Dominus regit me" No. 1 (33), dated January 1940. However, the paper seems to have been introduced in the course of preparing an undated set of parts (included in A 1.5) for the second version of String Quartet No. 1 (28.1), since the Violin I part is written on type 122, and the others on type 124; these parts were probably written late in 1939 (see note on type 122 paper). At the other end of the range, the Moon Songs (40) were drafted (A 3.56) on type 124, and an ink fair copy of each song (A 14.42, A 14.41, A 14.44, A 14.40), each dated July 1940, was prepared on the same paper. The range may extend somewhat beyond July, as type 124 was also used for a pencil chorus score (C 1.31) for the first movement of Leaves of Grass (41.1), which was performed on 9 October 1940. But this appears to have exhausted the supply, as all of the other performance material (C 1.31, A 1.39, A 4.17) was written on successor papers, types 126 and 127.

\section{July-September 1940}

Albert Pelletier. 12-stave folio, "No. 6," "Piano et chant," with logo and text at the foot of each recto. Printed braces group the staves in threes.

A small supply was used in the summer of 1940 to prepare additional copies of the Moon Songs (40). Three of these (A 14.35, A 14.36, A 14.37) are marked with the date of composition, July 1940. But they were probably prepared somewhat after that date: an undated ink score (A 12.24) of the fourth song, on type 125 paper, incorporates pencil revisions written on another, apparently earlier, ink score (A 14.40) written on type 124 and dated July 1940. Type 125 was also used for an ink score (A 14.43) of the song Wanderthirst (43), dated September 1940.

Albert Pelletier. 12-stave folio, "No. 5-12," "Imprimé en Canada," with logo (6.5 $\mathrm{mm}$ high) and text at the foot of each page, "Imprimé en Canada" lacking on the first recto. 
This paper is identical to type 127, except that the phrase "Imprimé en Canada" is missing from the first recto of each folio. It is used concurrently with type 127 and may represent defective folios of that type rather than a separate purchase. Eleven folios have been located in scores of completed works. Three of these appear to have been prepared for the performance of the Montreal Women's Symphony Orchestra that took place on 9 October 1940: an ink chorus score (C 1.31.2) for the women's choir arrangement of the first movement of Leaves of Grass (41.1); a single Violin I part in the set of parts (A 4.17) for the same movement; and a single Alto II part in a group of women's chorus parts (A 1.38) for $O$ Canada (39), God Save the King (38.1), and Rule Britannia (42). A fourth folio contains a score (A 18.47), dated March 1941 , of the song The Ship of Rio (48). The vocal line is written in ink, with pencil revisions that are incorporated into other copies; the piano part is written in pencil. Thus the score appears to be a working copy, rather than a fair copy prepared later, and the date can therefore be assumed to apply to the paper. The remaining seven folios were used for drafts (C 1.35.1) of Britannia: A Joyful Overture $(45,45.1)$, completed in February 1941. A larger quantity of type 126 paper, fourteen folios in all, is found in pencil scores of incomplete works: the first movement of a Sonata for Organ (A 1.7); a fragment for organ, possibly related to the same work (A 3.16); and the short score of a fragment for orchestra (C 1.17), of which the orchestral score (C 1.18) is written on type 119 paper (April 1939-December 1940).

\section{September 1940-July 1941}

Albert Pelletier. 12-stave folio, "No. 5-12," "Imprimé en Canada," with logo (6.5 $\mathrm{mm}$ high) and text at the foot of each page.

Extensively used for about a year beginning in the summer of 1940 . The paper appears to have come into use as type 124 was running out: the chorus score of the arrangement for women's choir of the first movement of Leaves of Grass (41.1) was drafted in pencil (C 1.31.1) on type 124 and copied in ink (C 1.31.2) on type 126; some chorus parts (A 1.39, C 1.31.3, A 4.17) and almost all of the orchestral parts (A 4.17), no doubt used in the performance on 9 October 1940, are written on type 127. The paper continued to be used well into 1941, as documented by two pencil scores (A 12.109, A 3.2), that of the Isabeau Variations (50), dated March 1941, and of the Intermezzo for Harp (52), dated July 1941. The range may extend slightly farther: part of a pencil short score (C 2.2.2) of the second movement of the Clarinet Concertino (56) is written on a half-folio that is probably type 127 (rather than the almost identical type 126); this carries no date, but the pencil score (C 2.2.1) of the complete work is dated October 1941. On the other hand, type 132, a successor paper, appears to have been purchased as a replacement by July 1941. The two types occur together in the parts for the version for harp and string quartet of the Three Sketches for Two Pianos (51.1); the harp part (C 2.19) is on type 127, and the string parts (A 3.47 [movements 1 and 2]; A 13.92 [movement 3]) on type 132. Those parts were probably used in the broadcast performance of the work, which took place, one movement each evening, on 16, 17, and 18 July 1941.

\section{November 1940?-February 1941}

Albert Pelletier. 24-stave folio, "No. 8-24-Symphonie," with logo and text at the foot of each page.

Used only in scores of Britannia: A Joyful Overture (45), the pencil score (A 3.33) of the first version, and the pencil and ink scores (C 2.1; A 21.1) of the final version, the last of these dated February 1941.

\section{March-July 1941}

Albert Pelletier. 12-stave folio, "No. 5-12" (inner pages), "No. 4-12" (outer pages), "Imprimé en Canada" (all pages), with logo (6.5 $\mathrm{mm}$ high) and text at the foot of each page.

This paper is identical to type 127, except that the designation "No. 5-12" is misprinted "No. 4-12" on the outer pages. It is used concurrently with type 127 and may represent defective folios of that type rather than a separate purchase. Only nine folios have been located; they occur in three scores (A 4.25, A 4.21, C 2.19), in each case along with one or more folios of type 127. Two occurrences are datable. The ink score (A 4.25) of the Isabeau Variations (50) is dated March 1941. It is the only extant ink score of the work, and a pencil score exists on type 127 paper (A 12.109), so there seems little reason to doubt that the ink score was written at the time of composition, or very soon after. The other datable occurrence is in the ink harp part (C 2.19) for the arrangement for harp and string quartet of the Three Sketches for Two 
Pianos (51.1); this part was no doubt used in the broadcast performance of that work, which took place, one movement each evening, on 16, 17, and 18 July 1941.

\section{May?-July 1941}

Albert Pelletier. 20-stave leaf, "P. 7-20," printed only on one side, with logo and text at the foot of each leaf.

There are just three occurrences, eighteen leaves in the pencil scores (A 13.89, A 13.90, A 13.92, one movement each) of the arrangement for harp and string quartet of the Three Sketches (51.1), another nine in the pencil score (A 13.91) of the orchestral arrangement of the first two movements of the same work (51.2), and twenty-two in the pencil score (A 19.11) of the Fantasia Concertante (53). Only the third occurrence is dated, "July 1941 " appearing in the caption. The first occurrence, though undated, is datable nevertheless. The three scores are marked with rehearsal letters in orange pencil and were no doubt used in the broadcast performance of the Sketches that took place, one movement each evening, on 16,17, and 18 July 1941. But they were possibly written in April or May. For, in late May or early June, Archer copied a score of Britannia: A Joyful Overture (45) on type 131 paper (see the note on that paper). A considerable quantity of type 131 remained and could have been used for the scores of the Three Sketches, had they been written in June. It seems likely, therefore, that type 130 was purchased in April or May, and used to prepare the arrangements of the Three Sketches soon after completion of the two-piano original. The flimsy leaves of this paper were unsuitable for the score of Britannia, and the quantity was insufficient, so type 131 was purchased. When that job was done, Archer apparently used up the remaining sheets of type 130 in the score of the Fantasia Concertante and then returned to type 131 in the fall to prepare the score of the Concertino for Clarinet in A and Orchestra (56).

\section{May 1941-Spring? 1944}

Albert Pelletier. 20-stave folio, "No. 9-20," with logo and text at the foot of each recto.

Available in quantity for about three years, from 1941 to 1944 . Some sixty folios have been located. The earliest dated use is in the pencil and ink scores (C 2.2.1, A 19.14) of the Concertino for Clarinet in A and Orchestra (56), both of which are dated October 1941. However, for reasons stated below, it is probable that the paper was used earlier, in May 1941, to prepare a score of Britannia: A Joyful Overture (45). The supply seems to have run out during the composition of the Symphony, of which the completed ink score (C 2.15) is dated September 1944. The pencil scores of the first movement (C 2.13) and the third movement (contained in C 2.15, overwritten in ink) were begun on type 131 and completed on an 18-stave successor paper used through 1946; the pencil scores of the second and fourth movements (again overwritten in ink and incorporated into $C 2.15$ ) were written entirely on the successor paper.

As noted above, there is evidence suggesting that type 131 paper was introduced in May 1941. In a verbal communication to the writer in September 1992, Archer recalled the visit to Montreal in 1941 of Arthur Bliss, who was en route from California to England to take up employment with the BBC. According to Archer, Bliss asked her mentor, Douglas Clarke, for scores of Canadian works, and at Clarke's request she prepared for Bliss a score of Britannia, a score that was used in the première and that became the property of the BBC. The event can be precisely dated: according to his autobiography, As I Remember (London: Faber and Faber, 1970), Bliss arrived in Montreal on 19 May 1941 (p. 134), spent time with Douglas Clarke on 3 and 4 June (p. 137), and boarded a ship for England on 5 June (p. 138). The score he took with him is of course not amongst Archer's papers, but there is evidence that it was written on type 131 paper. Laid into the ink score (C 1.37.2) of the two-piano arrangement of Britannia is a single leaf of type 131 (C 1.37.3) on which is written pages 21 and 22 (mm. 81-88) of the orchestral score, in a version that agrees with the pencil orchestral score (C 2.1) but not with the completed ink score (A 21.1). This leaf is written in black ink, and, while it is undoubtedly in Archer's hand, it displays clearer, more elegant penmanship than anything else encountered amongst her manuscripts. On unused staves on the recto of this leaf (p. 21) is a pencil draft in short score of a revision of mm. 83-86. In the ink score (A 21.1) of Britannia, written on type 128 paper, the leaf containing pp. 21 and 22 has been cut out and replaced with a leaf (i.e., a half-folio) of type 131, which incorporates the revision. On this leaf, the score was first written in pencil and then overwritten in black ink. Apparently then, Archer wrote a score of Britannia on type 131 paper. The care that she took over it, together with the fact that the paper is known to have been available soon after June 1941, suggests that this score was the one that she recalls preparing 
to give to Bliss. Having completed the copy, she decided for some reason to revise $\mathrm{mm}$. 83-86. So she cut out the leaf ( $\mathrm{C}$ 1.37.3) containing those measures and used it to draft the revision in short score. She then wrote a pencil full score on a half-folio of type 131, went over it in ink, and used it to insert the revision into her original ink score (A 21.1). Finally, she presumably made a fair copy of the two pages on another half-folio of type 131 and pasted it into the newly-copied score as a replacement for the leaf (C 1.37.3) that had been cut out.

\section{July 1941-March 1942}

Albert Pelletier. 12-stave folio, "No. 3A-12," with logo (7 mm high) and text at the foot of each page.

Available in quantity for about nine months beginning in July 1941. The limits are set by an ink score (A 12.101) of the second of the Three Preludes for Piano (54), dated July 1941, and by an ink score (included in A 15.73) of the first movement of the Quartet for Flute, Oboe, Clarinet, and Bassoon (60), dated March 1942. Since these are ink scores, it is possible that they were written some time after the composition dates that they bear. But other evidence suggests that type 132 had been purchased as a replacement for type 127 by early July 1941 (see notes on type 127). Similarly, there is evidence to suggest that the supply of type 132 ran out about the end of March 1942. Only the first movement of the Quartet is written on this paper, a pencil score (C 2.7.1) and the ink score cited above. A pasted-in revision to the pencil score, the pencil scores (C 2.7.2, C 2.7.3) of the second and third movemments, and the ink score (A 13.88) and parts (A 2.40, A 3.13) for the complete work are all written on the successor paper, type 133. At least some of those manuscripts must have been in existence before 13 April 1942, since the first three movements of the work were premièred on that day.

\section{March-December? 1942}

Albert Pelletier. 12-stave folio, "No. 3A-12," with logo (7 mm high) and text at the foot of three of the four pages, but lacking on the verso of the first leaf.

A successor to type 132, probably purchased in March 1942, and known to have been in use by 13 April of that year (see notes on type 132). Although some sixty folios have been located in scores of completed works, none bear dates of composition. The only date that does occur, "Friday June 5 th, 4 pm," is consistent with 1942 and appears to be a memorandum of an upcoming appointment, written on a page of pencil sketches (A 13.95.1) for the fourth movement of the Quartet for Flute, Oboe, Clarinet, and Bassoon (60), the first three movements of which were performed on 13 April 1942. Further evidence of the use of the paper in 1942 is provided by the pencil score (C 2.9) of the Sonatina for Piano No. 1 (61); that score must have been written before 25 November 1942, since the work was premièred on that day. The supply appears to have run out around the end of the year, a conjecture suggested by the absence of occurrences requiring a later date and supported by the appearance of a successor paper in the materials for the Sonata for Flute, Clarinet, and Piano (63), a work thought to have been completed in February 1943. The scores and parts for that work, including a pencil score (A 18.60) requiring thirteen folios, are all written on type 134.

\section{January 1943 -early 1946 ?}

Albert Pelletier. 12-stave folio, "No. 5-12," "Imprimé en Canada," with logo (6.5 $\mathrm{mm}$ high) and text at the foot of each recto.

A successor to type 133, available in quantity from early 1943 until late 1944, and possibily through early 1946. Some ninety folios have been located. The first datable occurrence is in the materials for the Sonata for Flute, Clarinet, and Piano (63), completed about February 1943, a pencil score (A 18.60), a score probably written in ink, of which only a photocopy (A 15.76) is extant, and two copies (A 3.27, A 15.75) of the flute part. Later, the paper was used in the pencil draft (A 2.2) of the music for Thirteen Clocks in Our Hut, written at the request of the diseuse, Chayele Grober. The première of this work, at Grober's recital on 22 November 1944, was reported the next morning on p. 3 of The Gazette (Montreal). Archer's recollection, communicated verbally to this writer on 11 November 1994, is that the performance date had already been set when Grober approached her about writing the music; composition, rehearsal, and performance all took place within a relatively short span of time. A 10-stave paper appears to have been purchased late in 1943 or in 1944, well before the supply of type 134 ran out. This was used in the scores (C 2.14.1, A 1.10) of the piano duet arrangement of the Symphony and may have been purchased because 
the remaining quantity of type 134 was insufficient for that purpose or because a 10-stave paper was considered more suitable. The determination of a precise date for the last use of type 134 is problematical and involves issues relating to the dating of compositions written well after the closing date of the present study.

\section{Chronological Catalogue of Compositions}

\section{Minuet and Trio for String Quartet. Between October 1932? and September 1933. \\ One movement: Alla minuetto.} Availability: Ms, A 1.35.1 / Not in Hartig.

Date of composition: The undated ink score (A 1.35.1) is written on pp. 1-2 of a 12-page booklet made of three folios of type 101 paper (October 1932?-Summer 1933?). The address "2163 Tupper Street" appears on p. 1 of the booklet, indicating that the score was written before September 1933.

$2 \quad$ Anthem. Between October 1932? and September 1933.

One movement: Allegro moderato, "Make a joyful noise unto the Lord." For soprano solo, SATB choir, and piano or organ / Text: Psalm 100:1-3, 5 (King James version) / Availability: Ms, A 1.35.2 / Not in Hartig.

Date of composition: The undated ink score (A 1.35.2) is written on pp. 3-8 of a 12-page booklet made of three folios of type 101 paper (October 1932?-Summer 1933?). The address "2163 Tupper Street" appears on p. 1 of the booklet, indicating that the score was written before September 1933.

$3 \quad$ Jig for Orchestra. June 1935 ?

One movement: Allegro.

2.2.2.2 2.2.0.0 \strings / Availability: Ms, C 1.4 / Hartig W21.

Date of composition: There are two undated scores, an ink short score (C 1.5) and a pencil full score (C 1.4), on type 102 paper. Accompanying each one is an identifying note by the composer, supplied when the scores were deposited in Calgary in 1980; these both provide "summer 1935" as the date of composition. Since the 10-stave leaves are unsuitable for an orchestral score (an extra staff had to be ruled to accommodate the Jig), it is tempting to think that the Jig preceded the Intermezzo for Orchestra (6) of August 1935, whose ink score (A 1.31.1) is written on more suitable 14-stave folios (type 103). And indeed Archer has indicated, in a verbal communication to the writer, that she recalls the Jig as her earliest orchestral composition. But the evidence provided by the paper is inconclusive: the only other occurrence of type 102, in the ink score (C 1.3.3) of an "exercise" is undatable, and similar 10-stave leaves (type 107) were used at a later date, in April 1936, for the pencil draft (A 1.25.2) of the orchestral score of the Miniature Suite (10).

4 Three Russian Folk Dances. Before 28 May 1936; July 1935?

1 Gopak: Allegro (1+pic.2.2.2 $\backslash 2.2 .0 .0 \backslash$ timp, cymbals, tambourine $\backslash$ strings).

2 Lesghinka: Allegro moderato (1+pic.2.2+bcl.2 $\backslash 2.2 .0 .0 \backslash$ timp $\backslash$ strings).

3 Kamarinskaia: Andantino (2(pic).2.2+bcl.2 $\backslash 2.2 .0 .0 \backslash$ timp $\backslash$ strings).

Arrangement for orchestra / Availability: Ms, A 1.32 / Earliest known performance: Montreal, 28 May 1936 (McGill Conservatorium Orchestra; Reginald de Haviland Tupper, conductor) / Not in Hartig.

Date of composition: The undated ink score (A 1.32) is written on type 103 paper (Summer 1935?). Two circumstances suggest that the Folk Dances may have been written before the Intermezzo for 
Orchestra (6), known to have been composed in August 1935. First, the ink score (A 1.31.1) of the Intermezzo is also written on the 14-stave type 103 paper, but could have been accommodated on twelve staves. The Russian Folk Dances, on the other hand, require thirteen staves. So it may be that the score of the Folk Dances was written first, motivating the purchase of type 103, which was then selected for the score of the Intermezzo simply because it was roomy and happened to be available. Second, both the parts (A 3.59, A 13.81) for the Russian Folk Dances and the ink short score (A 1.31.2) of the Intermezzo are written on type 104 paper, the short score being dated August 1935 and representing the earliest dated occurrence of type 104. However, Archer used more than one hundred folios of that paper over the course of the next year, and it seems likely that such a substantial purchase would have been motivated by a substantial project. The parts for the Folk Dances, which consumed about fifteen folios, represent the only possibility available in the summer of 1935, and it seems likely therefore that the paper was purchased for that project and used subsequently for the short score of the Intermezzo, which required only a single folio. The composer's note on the Russian Folk Dances, provided with a single page of a violin I part (C 1.7) when it was deposited at the University of Calgary in 1980, supplies 1936 as the date of composition.

Earliest known performance: Program.

\section{Serbian Folk Dance (Kokonyéchté Arabe). Before 28 May 1936; July 1935 ?}

One movement: Moderato.

Arrangement for orchestra $(2.2 .2+b c 1.2 \backslash 2.2 .0 .0 \backslash$ timp, tambourine, snare drum \ strings) / Availability: Ms, A 1.34 / Not in Hartig.

Date of composition: The Serbian Folk Dance seems to have been written at the same time as the Three Russian Folk Dances (4). The undated ink score (A 1.34), like the score of the Russian Folk Dances, is written on type 103 paper (Summer 1935?). And the Serbian Folk Dance is included in the only extant set of parts (A 3.59) for the Three Russian Folk Dances; although it follows the Russian Folk Dances in those parts, it does not appear to be a later addition.

$6 \quad$ Intermezzo for Orchestra. August 1935.

One movement: Andantino.

2.2.2.2\2.0.0.0 \strings / Availability: Ms, A 1.31.1 / Première: Montreal, 28 May 1936 (McGill Conservatorium Orchestra; Reginald de Haviland Tupper, conductor) / Hartig W20.

Date of composition: The ink score (A 1.31.1) and ink short score (A 1.31.2) are both dated August 1935.

Première: Data from program. The conductor's autograph on the ink score (A 1.31.1) includes the date 29 May 1936 (presumably 28 May was intended), and the phrase "first performance on earth."

$7 \quad$ Fugue on Given Subject. March 1936.

One movement: Allegro.

Four-voice fugue for "strings" / Availability: Ms, C 1.8.2 / Not in Hartig.

Date of composition: Drafts, partly in pencil and partly in ink, appear on pp. 16, 20, 21, 24, 32, 33, and 34 of a counterpoint notebook (A 3.25.2). The draft on p. 33 is dated 3 March 1936; an incomplete ink score (A 3.25.3) laid into the notebook is dated 18 February 1936 . The complete ink score (C 1.8.2) is dated March 1936.

Sanctus. March 1936.

One movement: No tempo indication.

Canon at the unison for SSS choir unaccompanied / Availability: Ms, A 3.25.5 / Not in Hartig. 
Date of composition: The two extant scores (A 3.25.4, A 3.25.5) are both written in ink, and both dated March 1936.

$9 \quad$ Mass in the Dorian Mode. April 1936.

1 Kyrie eleison I: Lento.

2 Christe eleison: Più lento.

3 Kyrie eleison II: Più mosso.

4 Gloria: Allegro.

5 Credo in unum Deum.

6 Sanctus: Moderato.

7 Benedictus: Andante.

8 Hosanna: Allegro.

9 Agnus Dei: Moderato.

For unaccompanied SATB choir (Benedictus for SAAAT) / Availability: Ms, A 13.84 / Hartig W132; W112 (Agnus Dei).

Date of composition: Ink scores with pencil revisions, of the complete Mass (A 13.64) and of the "Agnus Dei" (A 3.25.6), are dated March 1936. A complete ink score incorporating the pencil revisions (A 13.84) is dated April 1936.

Agnus Dei: In addition to the two extant scores of the Mass (A 13.64, A 13.84), there are two scores of the "Agnus Dei" alone. The first (A 3.25.6) is an ink score dated March 1936, written on one folio of type 104 paper (July 1935?-October 1936) laid into a notebook (A 3.25.1) containing counterpoint exercises whose dates range from December 1935 to March 1936. The "Agnus Dei" may thus have been written as an exercise in a counterpoint class and was possibly the first movement to be composed. The other separate score of this movement (C 1.6) is an ink score written on type 110 paper (September 1936-March 1938); its markings indicate that it was entered in the Quebec Musical Competition Festival in March 1938. No score of a different setting of the Agnus Dei text, corresponding to Hartig's entry W112, has been located.

$10 \quad$ Miniature Suite for Orchestra. April 1936.

1 Prelude: Largamente.

2 Allegretto grazioso e leggiero.

3 Canzonetta: Andante.

4 Allegro giocoso.

2.2.2.2 \2.0.0.0 \strings / Availability: Ms, A 14.20 / Première of second movement: Montreal, 20 May 1937 (McGill Conservatorium Orchestra; Reginald de Haviland Tupper, conductor) / Not in Hartig.

Date of composition: Both the ink short score (A 1.25.1) and the ink full score (A 14.20) are dated April 1936.

Première: Data from program. H. P. Bell's review of the concert (The Montreal Daily Star, 21 May $1937,15)$ refers to the movement as "a new work," suggesting that this was the première.

Instrumentation: The parts (A 3.60) include, for the fourth movement, a piccolo part which is not in the score. This is written on type 110 paper (September 1936-March 1938), suggesting that it may have been added around the time the second movement was performed; all of the other parts are written on type 104 (July 1935?-October 1936) and thus appear to have been written soon after the work was composed.

11 Scherzo and Andante for String Orchestra. August 1936.

1 Scherzo: Allegro molto.

2 Andante. 
Availability: Ms, A 1.33 / Earliest known performance: Montreal, 17 December 1936 (McGill Conservatorium Orchestra; Reginald de Haviland Tupper, conductor) / Not in Hartig.

Date of composition: The ink score of the Scherzo (A 1.33.1) is dated August 1936, that of the Andante (A 1.33.2) July 1936.

Earliest known performance: Program.

\section{Song. September 1936.}

One movement: Moderato, "I dare not ask a kiss."

For voice (d1-a2) and piano / Text by Robert Herrick, the poem "To Electra" from Hesperides, printed in The Poetical Works of Robert Herrick, ed. F. W. Moorman (Oxford: at The Clarendon Press, 1915), 231 / Availability: Ms, C 1.9.1 and C 1.9.2 / Not in Hartig.

Date of composition: The two extant scores (C 1.9.1, C 1.9.2) are dated September 1936 and October 1936. They are both in ink, and present identical versions of the song; the later one seems to have been prepared to eliminate a page turn.

Fugue. October 1936.

One movement: Andante.

Four-voice fugue, medium of performance unspecified / Availability: Ms, C 1.8.1 / Not in Hartig.

Date of composition: The only extant score (C 1.8.1) is written in ink and dated October 1936.

Medium of performance: Since the score is written on two staves, it may be intended for keyboard.

\section{Suite in G Major for Harpsichord, by Maurice Greene, Arranged for Strings. Before 10 January 1939; Fall 1936? \\ 1 Prelude: Allegro. \\ 2 Sarabande: Andante. \\ 3 Minuetto: Allegro.}

Arrangement for string orchestra / From British Library Add. Ms. 31467, one of ten suites by Greene on fols. 86r-108v / Availability: Ms, A 4.4 / Earliest known performance: Montreal, 10 January 1939 (McGill Conservatorium String Orchestra; Reginald de Haviland Tupper, conductor) / Not in Hartig.

Date of composition: The undated ink score (A 4.4) is written on type 109 paper (July 1936-February 1937). The set of twenty-three parts (A 4.5) is written principally on type 115 paper (April-August 1938), with three parts on type 113 (March 1938-December 1939) and one on type 114 (March 1938-April 1939). These appear to have been prepared between March and August 1938, along with the parts for the Variations on an Original Theme (20.1); no doubt plans for the performance of the two works, on 10 January 1939, were confirmed the previous summer.

Source: A modern edition appears on pp. 61-65 of the following publication: Maurice Greene, Voluntaries and Suites for Organ and Harpsichord, Recent Researches in the Music of the Baroque Era, no. 19 (Madison: A-R Editions, 1975). This edition cites the manuscript source as noted above but does not give the precise location of this suite. Archer's source was probably the following publication (not seen by the present writer): Maurice Greene. 3 Suites ... edited and arranged for pianoforte from mss. in the British Museum by Patrick Williams (London: J. Williams, 1935).

Earliest known performance: Program. The movement titles given on the programme (Allmanda, Sarabanda, Minnetto [sic]) match those that appear in the A-R Editions publication. 
15 Choruses from "The Bacchae" (Euripides). April 1937.

One movement: Andante con moto, "Will they ever come to me, ever again, the long, long dances."

For A solo, SSA choir, and orchestra (2+pic.2.2.2\4.2.3.0 \timp, tambourine, cymbals, harp or piano \strings) / Text selected from The Bacchae of Euripides, translated into English rhyming verse by Gilbert Murray (London: Allen \& Unwin, 1904) / Availability: Ms, A 17.83 and C 1.13 / Hartig W119.

Date of composition: A series of three ink vocal scores (A 3.63, A 3.64, A 3.50) can be arranged chronologically by observing that revisions to one are incorporated into the next. The later two are undated; the earliest (A 3.63) is dated January 1937. Two ink full scores (C 1.13, A 17.83) are both dated April 1937; the second has markings indicating that it was entered in the Quebec Musical Competition Festival in March 1938.

16 Kyrie No. 1. 1937?

One movement: Andante, "Lord, have mercy upon us."

For SATB choir unaccompanied / Availability: Ms, A 1.15 / Not in Hartig.

Date of composition: The only extant score is written in ink on one leaf of type 112 paper (February?-June 1937).

17 Prelude No. 4 in C-sharp Minor, by J. S. Bach, Arranged for Orchestra. 1937?

One movement: Andante con moto.

Arrangement for orchestra (2.2.2.2 \2.2.0.0 \strings) / From The Well-Tempered Clavier, Book 1, no. 4 / Availability: Ms, A 3.65 / Not in Hartig.

Date of composition: Undated scores in pencil (A 3.61) and in ink (A 3.65) are written on type 110 paper (September 1936-March 1938). The set of parts (A 3.62) is written principally on type 115 (April-August 1938), with four copies of the Violin I part on type 113 (March 1938-December 1939).

Rhapsody for Orchestra. August 1937.

One movement: Allegro non troppo e appassionato.

2.2.2.2 \4.2.3.0 \timp \strings / Availability: Ms, C 1.28 / Hartig W27.

Date of composition: The ink short score (C 1.16) is dated August 1937. The only extant full score (C 1.28) is undated; it is written in pencil on type 111 paper (April 1937-March 1938).

Silver. September 1937.

One movement: Lento, "Slowly, silently, now the moon."

Song for voice (c1-f2) and piano / Poem by Walter de la Mare, from Peacock Pie: A Book of Rhymes (New York: Henry Holt, 1924), 112 / Availability: Ms, A 4.77 and C 1.24 / Hartig W199.

Date of composition: There are two extant scores, both written in ink. One (A 4.77) is dated September 1937. The other (C 1.24) is undated, but has markings indicating that it was used as an entry in the Quebec Musical Competition Festival in March 1938.

Variations on an Original Theme. September 1937.

1 Theme: Andante.

2 Variation 1: Allegro. 
3 Variation 2: Andante con moto.

4 Variation 3: Allegro molto.

5 Variation 4: Andantino ben ritmato.

6 Variation 5 (Finale): Largamente.

First version, for orchestra (2(pic).2.2.2 \4.2.3.0 \timp \strings) / Availability: Ms, A 3.40 / Hartig W24.

Date of composition: The ink short score (C 1.19.6), written on type 110 paper (September 1936-March 1938), is dated September 1937, as is the ink full score (A 3.40), on type 111 (April 1937-March 1938). The pencil full score (C 1.14), also on type 111, is undated.

Chronology of versions: Two features of the short score suggest that the orchestra version is earlier than either of the string orchestra versions. First, its caption reads "(Original) Theme and Variations (for String Orchestra)," but the word "string" is clearly an insertion. Second, the theme, as it was originally written in the short score, corresponds to the full score of the orchestra version. But a revision of the theme appears in pencil on the recto of leaf 6 of the short score, and it is this revision that is used in both of the string orchestra versions. Two other circumstances suggest a chronology for all three versions. First, the title of the work varies from score to score, and arranging the forms of the title into a logical sequence suggests the order in which the scores were written. The short score's caption, centred on two lines, originally read "Theme and Variations (for Orchestra)." The word "Original" appears to have been added later: enclosed in parentheses, it is written in smaller letters at the left of the first line, upsetting the balance of the centred heading. The pencil score of the orchestra version copies this adjusted form; its title reads "Original Theme and Variations." The ink score presents a further revision: "Variations on Original Theme for Full Orchestra." The score (A 2.45) and parts (A 3.21) of one of the string orchestra versions copies the final title of the orchestra version: "Variations on Original Theme for String Orchestra." But the other string orchestra version varies the title slightly, suggesting that it came later; the score (A 1.14) has "Variations on an Original Theme for String Orchestra" and the parts (A 3.36; one bass part at C 1.15) have just "Variations on an Original Theme." Second, the paper types used suggest the same chronology as the evolution of the title. Details are provided above and in the notes on the two string orchestra versions.

20.1 Variations on an Original Theme. Between September 1937 and 10 January 1939; Summer 1938 ?

1 Theme: Andante moderato.

2 Variation 1: Più mosso.

3 Variation 2: Andantino con moto.

4 Variation 3: Allegro scherzando.

5 Variation 4: Quasi adagio.

6 Variation 5: Largamente.

Second version, for string orchestra / Availability: Ms, A 2.45 / Earliest known performance: Montreal, 10 January 1939 (McGill Conservatorium String Orchestra; Reginald de Haviland Tupper, conductor) / Not in Hartig.

Date of composition: The ink score (A 2.45) is written on type 115 paper (April-August 1938) and dated September 1937 (the date of composition of the original full orchestra version of the work).

Earliest known performance: Program. There seems little doubt that it was this second version that was performed on 10 January 1939. The score (A 2.45) contains conductor's cues in orange pencil; the third version of the work (20.2) seems not to have been prepared until after the performance.

20.2 Variations on an Original Theme. May 1939?

1 Theme: Andante moderato.

2 Variation 1: Più mosso.

3 Variation 2: Andante con moto. 
4 Variation 3: Allegro scherzando.

5 Variation 4: Quasi adagio.

6 Variation 5: Largamente.

Third version, for string orchestra / Availability: Ms, A 1.14 / Earliest known performance: see notes below / Not in Hartig.

Date of composition: The ink score (A 1.14) is written on type 122 paper (May-November 1939) and dated September 1937 (the date of composition of the original full orchestra version of the work). The parts (A 3.36; one bass part at C 1.15) are undated, and written on eleven folios of type 122, along with five folios of type 121 (April-June 1939) and two of type 120 (April-June 1939). For a reason detailed in the note on paper types 120,121 , and 122, the parts appear to have been written before July 1939.

Earliest known performance: It is possible that a broadcast of this version took place on 23 September 1939. Archer's files include an unidentified, undated clipping from a Montreal newspaper, which announces a broadcast performance of the work by "Alfred Wallenstein's Symphonic Strings" to take place on "Saturday, September 23" (a date consistent with 1939) over the Mutual Network in the United States and the CBC in Canada. The announcement notes that the "work received its première last January [i.e., 10 January 1939] at a concert given here by the McGill String Orchestra." The third version was available by September 1939 and may even have been prepared for that occasion. On the other hand, only the score (A 2.45) of the second version shows signs of use.

\section{Variations on a French-Canadian Folk Song. 29 October 1937. \\ 1 Theme: Semplice. \\ 2 Variation 1. \\ 3 Variation 2: Dolce. \\ 4 Variation 3: Allegretto scherzando. \\ 5 Variation 4: Andantino. \\ 6 Variation 5. \\ 7 Variation 6: Presto. \\ 8 Variation 7: Con moto. \\ 9 Variation 8: Andante cantabile. \\ 10 Finale: Allegro molto.}

First version, with nine variations, for piano / The folk song: "À la claire fontaine" / Availability: Ms, A 1.3.1 and A 4.6 / Hartig W37.

Date of composition: There are three ink scores (A 1.29, A 1.3.1, A 4.6). A 1.29 appears to have been written first, and presents the theme with eight variations. However, on the blank verso of the title page, two alternative versions of the theme are written in pencil. One of these is crossed out, but the other appears in A 1.3.1 as the theme; the theme and eight variations of A 1.29 appear in A 1.3.1 as variations 1 through 9. A 4.6 is a copy of A 1.3.1 and has been marked to indicate that it was used as an entry in the Quebec Musical Competition Festival held in March 1938. All three scores are dated 29 October 1937, but the score which presents the final version of the work (A 1.3.1) may have been written somewhat after that date.

Tempo indications: There are some discrepancies amongst the three scores; the indications given above are those that appear in A 4.6.

21.1 Variations on a French-Canadian Folk Song. March 1938.

1 Theme: Larghetto.

2 Variation 1: Tempo primo.

3 Variation 2: Tempo I.

4 Variation 3: Allegro molto. 


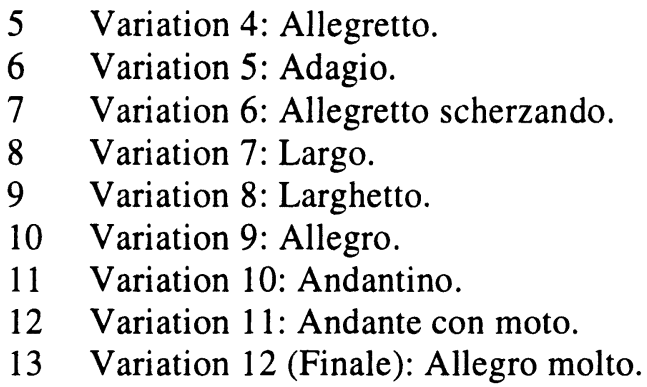

Second version, with twelve variations, for orchestra (2+pic.2.2.2 4 4.2.3.1 timp, cymbals, harp or piano \strings); the movements added in the orchestral version are variations 3,6 , and 7 / The folk song: "À la claire fontaine" / Availability: Ms, A 14.13 / Hartig W37.

Date of composition: The ink score (A 14.13) is dated March 1938.

Chronology of versions: One of the ink scores (A 4.6) of the piano version has a pencil note on the title page in Archer's handwriting, probably added some time after the score was written: "arranged from orchestral composition." But Archer advised, in a verbal communication to the writer on 16 November 1990 , that the piece was written first for piano and then orchestrated. It is this sequence that is suggested by the extant scores. In the first place, the scores of the piano version are all dated 29 October 1937; the ink score of the orchestra version is dated March 1938. Second, there is a transitional version that exists only as an undated pencil full score (C 1.10.1). It is written on thirteen folios of type 111 paper (April 1937-March 1938). The first eleven folios are arranged in a single gathering and present an orchestration of the piano version, with theme and nine variations. Several alterations, noted on this score either in pencil or in ink, are incorporated in the ink score (A 14.13) of the final orchestral version. Of the remaining two folios of C 1.10.1, the first contains abandoned material, but the second contains a draft that is incorporated into the final orchestral version as variation 7. Drafts of the other two variations new in this version, nos. 3 and 6 , have not been located.

22 Improvisation for Organ. 30 November 1937.

One movement: Non troppo lento. Availability: Ms, A 4.30 and A 4.26 / Hartig W243.

Date of composition: There are three ink scores (A 13.65, A 4.30, A 4.26), all dated 30 November 1937. A 13.65 appears to have been written first, as it lacks a title page, tempo indication, and marks of articulation, all of which have been added in A 4.30. A 4.26 has markings that indicate that it was used as an entry in the Quebec Musical Competition Festival of March 1938.

Variations on a French-Canadian Folk Song. Second version, with twelve variations, for orchestra. March 1938. See: 21.1.

Variations on an Original Theme. Second version, for string orchestra. Between September 1937 and 10 January 1939; Summer 1938? See: 20.1.

23 Prelude on "Aeterna Christi munera." Between July 1938 and April 1939; August 1938?

One movement: Maestoso.

Chorale prelude for organ / Availability: Ms, A 4.69 / Earliest known performance: Montreal, 25 February 1939(Violet Balestreri); on a recital shared with 
Phillips Motley and Graham George, sponsored by the Canadian College of Organists, Montreal Centre / Hartig W222; W229 (Eight Chorale Preludes).

Date of composition: There are two ink scores. One (C 1.10.2) is written on two folios of type 115 paper (April-August 1938) and dated July 1938; the other (A 4.69) is undated and written on three folios of type 116. Laid into C 1.10 .2 is an additional half-folio of type 115 containing an insert written in pencil, and many other revisions are noted on the score itself. All of this is incorporated into A 4.69, which, clearly, presents the finished work. It is possible (see note on type 116 paper) that this score was written as late as April 1939, even after the performance on 25 February 1939. But since the period of availability of type 115 is particularly well established, it seems unlikely that the revisions to $C 1.10 .2$, which consumed an additional half-folio of that paper, could have been made after the end of August 1938. And the revisions are so extensive that the manuscript has the appearance of a rough draft, making it probable that the fair copy (A 4.69) was prepared almost immediately.

Earliest known performance: Program.

\subsection{Aeterna Christi munera. Revised 1976.}

One movement: Maestoso.

Chorale prelude for organ, revised version / Availability: CMC / Hartig W222; W229 (Eight Chorale Preludes).

Date of revision: One of the ink scores of the first version (A 4.69) has pencil revisions that are incorporated into the CMC score. That score appears in the CMC accession list for 1 July-15 October 1977; the catalogue worksheet for the score at CMC Toronto says "revised 1976." The BMI Canada registration form is dated 26 July 1977.

Poem for Orchestra. Between March 1938 and April 1939; Fall 1938? One movement: Andante moderato.

2.2.2.2 \4.2.3.0 \timp, harp \ strings / Based on "The Nun," a poem by Humbert Wolfe, from his Requiem (London: Ernest Benn, 1927), 41-42 / Availability: Toronto: Berandol Music, 1979; study score has publisher's no.: BER 1793 / Earliest known performance: Oklahoma City, 9 December 1956 (Oklahoma City Symphony Orchestra; Guy Fraser Harrison, conductor) / Canadian première: Ottawa, 25 March 1959, (Ottawa Philharmonic Orchestra; Thomas Mayer, conductor) / Recording: CMC tape T 2043, from a CBC broadcast, 16 November 1973 (Atlantic Symphony Orchestra; Kenneth Elloway, conductor) (10:37) / Hartig W25; W36 (reference from alternate title).

Date of composition: Two ink short scores (A 18.66, A 4.24) are dated 19 March 1938 and March 1938 respectively. The latter is written on type 116 paper and seems to have been written in July or August 1938 (see note on type 116). It carries a pencil note in Archer's handwriting, "I am orchestrating this at present," suggesting that the orchestration was done, at the earliest, in the fall of 1938. Possibly the work of preparing parts for the Variations on an Original Theme (20.1) and the string orchestra arrangement of Maurice Greene's Suite in G Major (14) intervened, causing this delay (see note on type 113 paper). The only extant full score (A 18.67) is undated and written in pencil on type 117 paper. It was completed before April 1939 (see notes on type 117). On Archer's 1959 list, the work is dated 1944.

Poem: No reference to "The Nun" appears in the published score. However, the poem is mentioned in the caption of one of the short scores (A 4.24) and on the cover of the other (A 18.66); a copy of the poem (handwritten, but not by Archer) is filed with A 4.24.

Performances: The Oklahoma City performance was announced on p. 8 of The Oklahoma Daily for 6 December 1956, but no program or press review has come to hand. Pan Pipes 50, no. 2 (1958): 39 , in the "Premières" section of the report on Archer's activities, listed a broadcast by the same performers on NBC's program "The Voice of America" on 13 January 1957. The program of the Ottawa performance is dated "Wednesday, March 25"; the year is confirmed by the Ottawa Citizen, 
21 March 1959, 24, which announces "the first public performance of ... Tone Poem for Orchestra (after its radio broadcast) ...," and by a letter from the treasurer of the Ottawa Philharmonic, dated 6 April 1959, conveying the cheque for the rental fee.

25 Midsummer Apathy. August 1938.

One movement: Lento - sognando.

For piano / Availability: Ms, A 4.34 / Hartig W253.

Date of composition: The ink score (A 4.34) is dated August 1938.

Argument. 1938?

One movement: Andante.

For piano / Availability: Ms, A 4.35 / Hartig W214.

Date of composition: The only extant score (A 4.35) is written in pencil on a single half-folio of type 114 paper (March 1938-April 1939). The date 1938 appears in the caption but looks like a recent addition. The composition seems to be complete, but the score has the appearance of a draft.

\section{Kyrie No. 2. Fall 1938?}

One movement: No tempo indication, "Lord, have mercy upon us." For SATB choir unaccompanied / Availability: Ms, C 1.19.2 / Not in Hartig. Date of composition: The only extant score (C 1.19.2) is written in pencil on two leaves of type 118 paper (September 1938-June 1939). The score is dated 1937, but this date appears to be a recent addition, made perhaps at the time of its transfer to the University of Calgary in 1980. The score is associated, in Archer's papers, with drafts (C 1.19.4, C 1.19.3, C 1.19.5) of movements 1, 3, and 4 of the first version of String Quartet No. 1 (28), completed in December 1938, making it probable that this Kyrie was composed in the fall of 1938 rather than in 1939.

28 String Quartet No. 1. December 1938.

1 Fantasy: Andante molto tranquillo.

2 Capriccio: Allegro.

3 Canzone: Andante molto moderato.

4 Rondino: Allegretto scherzando.

First version / Availability: Ms, A 16.51.1 / Not in Hartig.

Date of composition: The ink score (A 16.51.1) is dated December 1938.

28.1 String Quartet No. 1. July 1939.

1 Andante molto tranquillo.

2 Scherzo: Allegro ma non troppo.

3 Theme and Variations: Adagio ma non troppo.

4 Rondo: Allegretto scherzando.

Second version. The original third movement was replaced, and the second movement extended by the addition of a trio. The first and last movements were not changed / Availability: Ms, A 1.5 and A 4.3 / Première (third and fourth movements only): Montreal, 7 March 1940 (McGill Conservatorium String Orchestra; Reginald de Haviland Tupper, conductor) / Hartig W92.

Date of composition: Two ink scores (A 1.5, A 4.3) are both dated July 1939.

Première: Data from program. A review in The Montreal Daily Star (8 March 1940, 17) describes these movements as "a quite new work." Comparison of the score (A 1.5) with the string orchestra 
parts for movements 3 and 4 (A 1.6) shows that the parts present the original form of the work, not an arrangement.

\section{Scherzo for String Quartet.}

\section{A fragment of five measures / Availability: C 1.21 / Hartig W69.}

The entry in Hartig reads, "Scherzo for String Quartet (1938) (Manuscript)." It has not been possible to associate this entry with any completed work. Hartig's entry is therefore thought to be based on entry 1.21 on the Box List for the Violet Archer Fonds at the University of Calgary: "Scherzo fragment for String Quartet. 1938." The information on the Box List was supplied by Archer when the papers were deposited in 1980. It refers to a five-measure fragment written in pencil on one side of a half-folio of paper of a type first used early in 1944, during the composition of the Symphony.

29 Six Pieces for Piano and Tympani. March (or April?) 1939.

1 Grecian Dance: Andantino con moto. March 1939.

2 Indian Lament: Adagio. 4 May 1938.

3 Jungle Dance: Andante molto moderato. March 1939.

4 Capriccio: Andante maestoso. April 1939?

5 Funeral March: Adagio. February 1939.

6 Scherzo: Allegro. August 1938.

Availability: Ms, C 1.25 / Earliest known performance: Nos. 2 and 3: Montreal, 28 July 1945 (Michel Perrault, timpani; Marie-Thérèse Paquin, piano), in a broadcast on radio station CBF. Complete work: Wichita, 30 June 1959 (Donn Salyer, timpani; Julie Stone, piano), in a recital at the University of Wichita School of Music / Inside front cover of Ms C 1.25: "To my friend May Fluhmann, assistant tympanist of the Montreal Orchestra" / Hartig W76.

Date of composition: Dated ink scores supply the dates of composition noted above for nos. 1-3, 5 and 6 (1: A 13.79; 2: C 1.19.9, A 13.77, A 13.69; 3: A 13.73; 5: A 13.78; 6: C 1.19.11, A 13.70). The only extant separate score of no. 4 is an undated pencil score (C 1.19.10) on type 114 paper (March 1938-April 1939). The ink score (A 2.21) of the orchestrated version (29.1) of this movement is dated April 1939; this could represent either the date of composition or of orchestration. An ink fair copy (C 1.25) of the Six Pieces is dated January 1939, but this date is a later addition and must be inaccurate (see note on type 114 paper).

Earliest known performance: Nos. 2 and 3: The Gazette (Montreal), 28 July 1945, 2, where the broadcast is described as the "first radio performance" of these two movements. Complete work: Program.

\subsection{Capriccio for Tympani and Orchestra. April 1939?}

One movement: Andante maestoso.

Arrangement for timpani and orchestra (2+pic.2.2.2 \4.2.3.1 \ cymbals $\backslash$ strings) of no. 4 of Six Pieces for Piano and Tympani / Availability: Ms, A 2.21 (two copies) / Hartig W4.

Date of arrangement: One copy of the ink score (A 2.21) is dated April 1939. Since it has not been possible to establish a precise date of composition for the original version for piano and timpani, it is not known whether this date refers to the composition of that version or to the completion of the arrangement. However, if the orchestration were not done in April 1939, then it must have been done very soon afterward, since it is highly probable that the parts (A 2.23) were written before July (see note on types 120,121 , and 122 paper).

Title: The title "Capriccio" is used on all of the manuscripts and on Archer's 1940, 1957, and 1959 lists. However, on her 1960 list, the title is "Concerto," and it is under that title that the work is listed 
in the CBC's Thirty-Four Biographies of Canadian Composers (1964) and several subsequent published lists.

\subsection{Grecian Dance. Spring 1940?}

One movement: Andantino con moto.

Arrangement for piano of no. 1 of Six Pieces for Piano and Tympani / Availability: Ms, C 1.27 / Hartig W239.

Date of arrangement: The only extant score (C 1.27) is written in blue ink on type 124 paper (December 1939-July 1940). It is signed "Violet Balestreri," indicating that it was written before 22 June 1940. The date on this score, "February 1939," is written in black ink; it may be an inaccurate later addition, intended to reflect the date of composition of the original version for piano and timpani, of which the ink score (A 13.79) is dated March 1939.

\subsection{Funeral March. Spring 1940?}

One movement: Adagio non troppo.

Arrangement for piano of no. 5 of Six Pieces for Piano and Tympani I Availability: Ms, A 13.68 / Not in Hartig.

Date of arrangement: The only extant score is written in ink on type 124 paper (December 1939-July 1940). It is dated February 1939, the date of composition of the original version for piano and timpani, and signed "Violet Balestreri," indicating that it was written before 22 June 1940.

30 Jesu, Joy of Man's Desiring, by J. S. Bach, Arranged for Piano. Spring 1939?

One movement: Simple and flowing. A "simplified arrangement" for piano / Availability: Ms, A 3.54 (two copies) / Not in Hartig.

Date of composition: Both copies of the score (A 3.54) are written in ink on type 121 paper (April-June 1939).

\section{$31 \quad$ Three Scenes (Habitant Sketches). 1939.}

1 Jig: Lively.

2 Church Scene: Very broadly.

3 Christmas in Quebec: Lightly, briskly.

For piano / Availability: New York: Mercury Music Corp., 1946; Toronto: Berandol Music, 1982. Nos. 1-2: In the Royal Conservatory of Music's Piano Repertoire Album (Oakville: Frederick Harris, 1988), Grade 5: 38-39, and Grade 6: 36-38, respectively / Première: Montreal, 25 November 1942 (Violet Archer, piano), on the twelfth of the Sarah Fischer Concerts / Recording: CMC tape T 456, from a CBC broadcast, 22 February 1967 (Elvira Lobe, piano) (4:30) / Hartig W240; W275 (reference from alternate title).

Date of composition: There are nine undated ink scores of these movements, one of no. 1, three of no. 2, and five of no. 3. Of these, four are identified as "revised" copies. All of the others, the earlier copies (no. 1: A 12.106; no. 2: C 2.6.2; no. 3: C 2.6.4, C 2.6.5, C 2.6.6), are written on type 122 paper (May-November 1939). The "revised" copies of no. 2 (C 2.6.1, A 12.107) are written one on type 122 paper and the other on type 121 (April-June 1939); those of no. 3 (C 2.6.3, A 12.108) are both written on type 124 (December 1939-July 1940). All of the scores are signed "Violet Balestreri," indicating that they were written before 22 June 1940. It seems probable, then, that these movements were all written in 1939 and that the (rather minor) revisions were complete by the 
middle of 1940. One of the scores of no. 3 (A 12.108) has an extensive pencil insertion, essentially a repetition of a portion of the movement, which does not appear in any of the other manuscripts but which is incorporated in the published score. It is possible that this revision was not made until the work was submitted for publication. When several of the manuscript scores were deposited at the University of Calgary in 1980, Archer supplied 1942 as the date of composition; on her 1959 list, the work is dated 1945.

Première: Program.

Variations on an Original Theme. Third version, for string orchestra. May 1939? See: 20.2 .

String Quartet No. 1. Second version. July 1939. See: 28.1.

Symphonic Suite. November 1939.

1 Little Prelude: Allegretto gioioso (2+pic.2.2.2 $\backslash 2.0 .0 .0 \backslash$ timp $\backslash$ strings). November 1939.

2 Andante moderato (2.2.2.2 $\backslash 2.2 .0 .0 \backslash$ strings). Between May and November 1939.

3 Scherzo: Allegro ma non troppo e giocoso (2+pic.2.2.2 $\backslash 4.2 .3 .1 \backslash$ timp, tambourine, snare drum, triangle, cymbals $\backslash$ strings). April 1939.

4 Fugato: Allegro energico (2+pic.2.2.2 \4.2.3.1 \timp, triangle, cymbals \strings). September 1939.

For orchestra / Availability: CMC / Première: Third movement: Montreal, 18 February 1940 (The Montreal Orchestra; Douglas Clarke, conductor). Complete work: Edmonton, 18 October 1991 (Edmonton Symphony Orchestra; Uri Mayer, conductor) / Hartig W33; W29 (third movement).

Date of composition: The ink short scores (A 1.4) of movements 3, 4, and 1 are dated April, September, and November 1939 respectively. The ink short score (A 1.4.2) of the second movement is undated, but written on type 122 paper (May-November 1939). The pencil and ink orchestral scores (A 14.12, A 18.49) are written on type 119 paper (April 1939-December 1940). In both short and orchestral scores, each movement is bound in a separate gathering, suggesting that each was orchestrated before the next was composed; the rather widely spaced dates on the short scores would have allowed time for such a procedure. In the ink score (A 18.49) each movement is dated August 1939. But these dates are written (in movements 1-3 certainly, and in movement 4 possibly) in an ink different from that of the score, and may therefore be inaccurate as a result of having been added some time after the scores were prepared.

Premières: Programs.

33 Prelude on "Dominus regit me" No. 1. January 1940.

One movement: Andante con moto e semplice.

Chorale prelude for organ / Availability: Ms, A 4.73.1 / Hartig W223; W229 (Eight Chorale Preludes).

Date of composition: The ink score (A 4.73.1) is dated January 1940.

Related works: Archer wrote three chorale preludes on "Dominus regit me." The third, like this first one, is in $6 / 8$ time and presents the tune unornamented in the pedal. It was composed in July 1960 , drafted in part on the ink score of the present work; it is apparent from the manuscript that Archer had set out to revise the first setting and ended by creating a new one. The second chorale prelude was written in 1949, a quite different treatment in $6 / 4$ time, which derives from the hymn 
melody without stating it. The third setting is available from the CMC; the second was published in 1962 by Peer International, along with the setting of Rockingham, as Two Chorale Preludes.

\section{Chorale Prelude on "Heinlein." February 1940?}

One movement: Largo - Maestoso.

For organ / Availability: Ms, A 4.33 / Hartig W224; W229 (Eight Chorale Preludes).

Date of composition: The undated ink score (A 4.33) is written on type 124 paper (December 1939-July 1940). Archer has stated, in a verbal communication to the writer, that she recalls writing the work to play at noon-hour services during Lent at which she volunteered as organist. In 1940, the first day of Lent was February 7; March 24 was Easter Day.

\subsection{Chorale Prelude on "Heinlein." Revised January 1960.}

One movement: Largo maestoso.

For organ, revised version / Availability: CMC / Hartig W224; W229 (Eight Chorale Preludes).

Date of revision: The ink score of the first version (A 4.33) has pencil revisions that are incorporated into the holograph transparencies from which the CMC score is reproduced. Archer's 1959 list of her works includes the typewritten entry, "Eight Chorale Preludes," followed by a note in her handwriting: "Two of these revised Jan. 1960 (Henlein [sic] and Dominus regit me)."

Tune name: On the score of the original version (A 4.33), the tune name is correctly spelled "Heinlein"; the name has been misspelled "Henlein" on the transparencies from which the CMC score is reproduced.

35 Prelude for Piano. March 1940.

One movement: Peacefully - with singing tone.

Availability: Ms, A 2.46 / Not in Hartig.

Date of composition: The pencil score (A 3.3) and the ink score (A 2.46) are both dated March 1940.

Title: In the pencil score, the work has the following title: "Spring: Prelude I."

36 Capriccio Fantastic. April 1940.

One movement: Allegretto.

For piano / Availability: Ms, A 3.6 / Earliest known performance: Montreal, 15 July 1941 (Ross Pratt), on a broadcast over station CBM and the CBC network, in the series "Masters of the Pianoforte" / Hartig 219.

Date of composition: The pencil score (A 3.6) is dated April 1940.

Earliest known performance: Announced in The Gazette (Montreal), 15 July 1941, 2.

Grecian Dance. Arrangement for piano of no. 1 of Six Pieces for Piano and Tympani. Spring 1940? See: 29.2.

Funeral March. Arrangement for piano of no. 5 of Six Pieces for Piano and Tympani. Spring 1940? See: 29.3. 
37 Two Easy Arrangements of Canadian Folk Songs. 1940?

1 Ah! si mon moine voulait danser! (If my old top were a dancing man).

2 Digue dindaine (Ding-a-ding-dain-a).

For piano / The folk songs selected from Chansons populaires du Canada, ed. Ernest Gagnon; in the 5th ed. (Montreal: Librairie Beauchemin, 1908) they appear on p. 129 and p. 50 respectively. The English translations are by J. Murray Gibbon, from Canadian Folk Songs (Old and New) (New York: E. P. Dutton, 1927), p. 48 and p. 2 respectively / Availability: Ms (pencil draft only), C 1.29.2 / Not in Hartig.

Sources and date of composition: Known only from pencil drafts on the versos of two half-folios (C 1.29) of type 124 paper (December 1939-July 1940); on the rectos is a pencil draft of part of the Capriccio Fantastic (36), of which a pencil score (A 3.6) is dated April 1940. An entry in Helmut Kallmann's Catalogue of Canadian Composers (Toronto: CBC, 1952) probably refers to these settings: "Two easy arrangements of Can. folk songs, piano, MS"; no other score matching Kallmann's description has come to hand.

\subsection{Two Easy Arrangements of Canadian Folk Songs. 1940?}

1 Ah! si mon moine voulait danser! (If my old top were a dancing man): Allegretto.

2 Digue dindaine (Ding-a-ding-dain-a): Lively. Arrangement for piano, four hands, of the piano solo version / Availability: Ms, A 12.51 / Not in Hartig.

Date of arrangement: A pencil score of the secondo part of no. 2 (C 3.5) is written on a quarter-folio of type 119 paper (April 1939-December 1940). No other composing scores have been located, but since C 3.5, together with the draft (C 1.29.2) of the Two Easy Arrangements of Canadian Folk Songs (37), presents all of the musical material, it is possible that none existed. The completed work is written in ink on four transparencies (A 12.51) of a type not encountered elsewhere. This score is signed "Violet Archer," suggesting that it could not have been written before 22 June 1940; in fact, it may have been written long after that date, as Archer is not known to have used transparencies until about 1946.

Title: On the transparencies (A 12.51), the work has the title: "Children's Duets; Two Canadian Folksongs Arranged for Four Hands."

Related works: With minor revisions, these duets were incorporated into the Ten Folk Songs for Four Hands, composed in 1952, where they appear as no. 1 and no. 2 of Book I.

God Save the King. Between April 1939 and 22 June 1940; early 1940? One movement: Maestoso.

Arrangement for orchestra, first version (3+pic.2+engh.2.2 \4.2.3.0 \timp, snare drum, harp \strings) / Availability: Ms, C 1.1.2 / Not in Hartig.

Date of composition: Both ink and pencil scores (C 1.1.2, C 1.1.3) are written on type 119 paper (April 1939-December 1940). The ink score is signed "Violet Balestreri," suggesting that it was written before 22 June 1940.

\subsection{God Save the King. July 1940?}

One movement: No tempo indication.

Arrangement for orchestra, second version (2+pic.2.2.2 2 2.2.0.0 \timp, cymbals, snare drum, piano \strings) / Availability: Ms, A 3.30 / Première: 
Montreal, 31 July 1940 (Montreal Women's Symphony Orchestra; Ethel Stark, conductor) / Hartig W18.

Date of composition, première: The undated pencil score (A 3.30) is written on type 119 paper (April 1939-December 1940). It is likely that this second version was prepared for the inaugural concert of the Montreal Women's Symphony Orchestra on 31 July 1940. Reviews of the concert (The Montreal Daily Star, 1 August 1940, 9; The Standard (Montreal), 10 August 1940, Photonews section, 16-19) state that the arrangements of God Save the King and $O$ Canada played on that occasion were made for the Orchestra by Violet Archer. The instrumentation of this second version is a close match for that of the other works performed, while the first version, work 38 , requires a larger wind complement. And the third version, while it was made for the Orchestra and is performable with the forces available on 31 July 1940, seems not to have been written until after that date (see notes on work 38.2).

38.2 God Save the King. Between May 1941 and early 1944.

One movement: No tempo indication.

Arrangement for orchestra, third version (2.2.2.2 \4.3.3.1 \timp, snare drum, bass drum, cymbals $\backslash$ strings $\backslash$ trumpet II, horn II and IV, trombones, and tuba may be omitted) / Availability: Ms, A 3.31 / On the title page of Ms A 3.31: "Specially arranged for Miss Ethel Stark and the Montreal Women's Symphony Orchestra" / Not in Hartig.

Date of composition: The only extant manuscript (A 3.31) is written in pencil on type 131 paper (May 1941-Spring? 1944). It also contains the score of the second version of $O$ Canada (39.1).

\section{9}

O Canada. July 1940 ?

One movement: No tempo indication.

Arrangement for orchestra, first version, in G major (2+pic.2.2.2 $\ 2.2 .0 .0 \backslash$ timp, snare drum, piano \ strings) / Availability: Ms, A 3.29 / Première: Montreal, 31 July 1940 (Montreal Women's Symphony Orchestra; Ethel Stark, conductor) / Hartig W23.

Date of composition, première: Like the second version of God Save the King (see note on work 38.1), this arrangement of $O$ Canada seems to have been prepared for the inaugural concert of the Montreal Women's Symphony Orchestra on 31 July 1940. The instrumentation matches the forces available on that occasion; and the undated pencil score (A 3.29) is written on type 119 paper (April 1939-December 1940), while the score of the second version is written on type 131 (May 1941-Spring? 1944). Furthermore, when the concert was repeated on 9 October 1940 with the addition of the first movement of Archer's choral cycle Leaves of Grass (41.1), chorus parts (A 1.38, C 1.1.6) were prepared so that the choir could participate in the performance of the national anthems. The parts for $O$ Canada are in $\mathrm{G}$ major, corresponding to the key of this first version, rather than that of the second, which is in E-flat major.

\subsection{O Canada. Between May 1941 and early 1944.}

One movement: No tempo indication.

Arrangement for orchestra, second version, in E-flat major (2+pic.2.2.2 । 4.3.3.1 \timp, snare drum, bass drum, cymbals $\backslash$ strings $\backslash$ piccolo, trumpet II, horn II and IV, trombones, and tuba may be omitted) / Availability: Ms, A 3.31 / On the title page of Ms, A 3.31: "Specially arranged for Miss Ethel Stark and the Montreai Women's Symphony Orchestra" / Not in Hartig.

Date of composition: The only extant manuscript (A 3.31) is written in pencil on type 131 paper (May 1941-Spring? 1944). It also contains the score of the third version of God Save the King (38.2). 
Moon Songs. July 1940.

1 The Haughty Snail King: Slowly, pompously, "Twelve snails went walking after night" (a-e2).

2 The Beggar Speaks: Very leisurely, "Come eat the bread of idleness" (b-e2).

3 What Grandpa Mouse Said: Briskly, with humor, "The moon's a holy owl-queen" (c1-f2).

4 The Rose of Midnight: Largo-tranquillo, "The moon is now an opening flower" (b-e2).

Song cycle for mezzo-contralto and piano / Words from "Moon Poems" by Vachel Lindsay, in his Collected Poems (New York: The Macmillan Company, 1925), 232, 243, 242-3, and 239 respectively / The original no. 4 withdrawn and replaced by a new setting of the same text composed in 1974 / Availability: Nos. 1-3, and 1974 setting of no. 4: CMC. Nos. 1-2: In Songs IV to English Texts, ed. Frederick A. Hall, The Canadian Musical Heritage, vol. 14 (Ottawa: Canadian Musical Heritage Society, 1993), 180-89. No. 3: In Whims: A Songbook for Children, ed. Roberta Stephen and Janice Thoreson (Calgary: Alberta Keys Music Publishing, 1986), 5-9, under the title "The Owl Queen." No. 4 (original setting): Ms, A 12.24 and A 12.98 / Earliest known performances: No. 2: Montreal, 3 November 1952 (Maureen Forrester, contralto; Charles Reiner, piano), on the 58th Sarah Fischer concert. Nos. 1-2: Oklahoma City, 7 October 1959 (Orcenith Smith, baritone; Lytle Powell, piano), on a recital sponsored by The MacDowell Club of Allied Arts. Complete work, with 1974 setting of no. 4: Edmonton, early 1976 (June Hunt, mezzo-contralto; Albert Krywolt, piano), on a broadcast over television station CFRN / Recording of no. 2: CMC tape $\mathrm{T}$ 330, recorded at a program of contemporary Canadian music presented at the University of Alberta in Edmonton on 21 November 1964 (George Ravenscroft, baritone; Patricia Elliott, piano) (3:30) / Hartig W186; W191 (no. 3, as published in Whims: A Songbook for Children).

Date of composition: Ink scores of nos. 1-4 (A 14.42, A 14.41, A 14.44, and A 14.40 respectively), and ink scores of nos. 1-3 (A 14.35, A 14.36, and A 14.37), are all dated July 1940.

Performances: Data on the 1952 and 1959 performances come from the programs. The 1976 performance was announced in Pan Pipes 68, no. 2 (1976): 37, in the "Premières" section of Archer's report, for "sometime in January 1976." June Hunt, in a verbal communcation to the writer on 10 November 1994, confirmed that the performance took place and provided the name of the television station. It has not proved possible to document this performance more precisely.

Recording: Data from the catalogue of the CMC sound recordings collection, with additional information from entry W186b in Hartig.

41 Leaves of Grass. 1940, probably before 9 October.

1 The Song of the Universal: Largo maestoso, "Come said the muse" (SATB choir, orchestra (2+pic.2.2.2 \2.2.2.0 \timp, cymbals, chimes, triangle $\backslash$ strings)).

2 Sea-Drift: Largo, "Two together!" (SATB choir (S divisi), orchestra (2.2.2.2 $\backslash 2.2 .0 .0 \backslash$ timp, cymbals, triangle $\backslash$ strings)). 
3 Beat! Beat! Drums!: Alla marcia ma moderato, "Beat! beat! drums!-Blow! bugles! blow!" (SATB choir (ST divisi), orchestra (2+pic.2.2.2 \4.2.3.1 \ timp, snare drum, bass drum, cymbals, tambourine, triangle, piano $\backslash$ strings)).

4 A Song of Joys: Allegro gioioso, "O to make the most jubilant song!" (SATB choir (A divisi), orchestra (2+pic.2.2.2 \4.2.3.1 \ timp, tambourine, triangle, snare drum, cymbals, piano \strings)). Suite for mixed choir and orchestra / Text from Leaves of Grass, by Walt Whitman (New York: Aventine Press, 1931): 1: From "Birds of Passage," subsection "Song of the Universal," selected lines on pp. 234-35. 2: From "Sea-Drift," subsection "Out of the Cradle Endlessly Rocking," selected lines on pp. 257-60. 3: From "Drum-Taps," subsection "Beat! Beat! Drums!," complete, pp. 290-91. 4: From "A Song of Joys," selected lines on p. 181; and from "A Song for Occupations," selected lines on p. 220 / Availability: Ms, C 1.32 (movements 1 and 2); A 3.41 (movements 3 and 4); A 2.37 (movement 2 only)/Premières of movement 2: With piano: Montreal, 5 June 1944 (Choir of Erskine and American United Church; Violet Archer, piano; Berkley E. Chadwick, conductor). With orchestra: Montreal, 8 May 1946 (Berkley E. Chadwick's Choir; Montreal Women's Symphony Orchestra; Ethel Stark, conductor) / Hartig W131.

Date of composition: All of the extant scores are undated. Ink vocal scores of the first three movements (A 14.6, containing movement 1; A 16.45 and A 18.68, both containing movements 2 and 3) are all written on type 124 paper (December 1939-July 1940). While the name "Archer" occurs on all three scores, the signatures have all been altered; the original appears in each case to have been "Violet Balestreri," suggesting that the scores were written before 22 June 1940. The pencil orchestral scores (C 1.32, containing movements 1 and 2; A 3.41, containing movements 3 and 4) are all written on type 119 paper (April 1939-December 1940). Only the second movement is signed; "Violet Archer" appears to be original, suggesting that the orchestration, at least of this movement, was prepared after 22 June 1940. The entire work may have been complete by 9 October 1940. On that date, the Montreal Women's Symphony Orchestra performed an arrangement of the first movement for women's chorus (41.1). The concert repeated the program of the Orchestra's inaugural concert on 31 July 1940, with the addition of the Archer work, suggesting that Leaves of Grass became available for performance at some time in August or September 1940 and that the arrangement of the first movement was prepared in response to this specific performance opportunity. On Archer's 1959 list, the work is dated 1940.

Premières: Data from program dated 5 June 1944. Reviews in The Gazette (Montreal), 9 May 1946, 3, and in The Monitor (Montreal), 16 May 1946, 9, provide data on the 8 May 1946 performance and indicate that these were the premières.

\subsection{Song of the Universal. 1940, before 9 October; August 1940?}

One movement: Largo maestoso, "Come said the muse."

The first movement of Leaves of Grass (41), the choral parts arranged for SSAA choir / Availability: Ms, C 1.33 / Première: Montreal, 9 October 1940 (Montreal Women's Symphony Orchestra, with a small women's choir organized for the occasion; Ethel Stark, conductor) / Not in Hartig.

Date of arrangement: A pencil chorus score of the SSAA version (C 1.31.1) is written on type 124 paper (December 1939-July 1940), and an ink copy (C 1.31.2) on type 126 (September 1940-March 1941). These scores may have been used, along with the pencil orchestral score (C 1.32.1) of the SATB version, to prepare the ink orchestral score (C 1.33) of the arrangement, which is written on type 119 paper (April 1939-December 1940). This score is signed "Violet Archer," suggesting that it was written after 22 June 1940. 
Première: The program is dated "Wednesday 9 October." A review by Thomas Archer appears in The Gazette (Montreal), 10 October 1940, 6; it states that the concert took place "last night" and refers to the performance of Archer's work as "the première of a tone poem for chorus and orchestra."

Rule Britannia. Between April 1939 and 9 October 1940; September 1940 ?

One movement: No tempo indication.

Arrangement for orchestra (pic+2.2.2.2 \2.2.2.0 timp, snare drum, bass drum, cymbals \strings) / Availability: Ms, C 1.1.1 / Hartig W28.

Date of composition: The undated pencil score (C 1.1.1) is written on type 119 paper (April 1939-December 1940). The chorus score (C 1.1.5) and many of the chorus parts (A 1.38) for God Save the King (38.1) and $O$ Canada (39), which were no doubt prepared for the use of the women's chorus that sang the first movement of Leaves of Grass (41.1) with the Montreal Women's Symphony Orchestra on 9 October 1940, also include Rule Britannia. This suggests that the arrangement was prepared in anticipation of a possible performance on that occasion. The program and reviews of the concert, however, do not indicate that Rule Britannia was performed.

\section{Wanderthirst. September 1940.}

One movement: With a well marked rhythm, but not too fast, "Beyond the East the sunrise."

Song for tenor (e-g1) and piano / Poem by Gerald Gould, printed in Gerald Gould (The Augustan Books of English Poetry, second series, ed. Humbert Wolfe, no. 20) (London: Ernest Benn, 1928), 1 / Availability: Ms, A 14.43 / Not in Hartig.

Date of composition: The ink score (A 14.43) is dated September 1940.

Sonatina for Organ. Between September 1940 and 1 March 1941; December 1940?

1 Andantino grazioso.

2 Adagio - ma non troppo.

3 Fughetta: Allegretto.

Availability: Toronto: Chanteclair Music, a division of Gordon V. Thompson Ltd., 1971 / Première: Trinity Memorial Church, Montreal, 1 March 1941 (Violet Archer), on a program of original organ music composed for the occasion by members of the Canadian College of Organists, Montreal Centre / In the published score: "Dedicated to Mildred Andrews, distinguished organist and teacher" / Hartig W265.

Date of composition: A single folio (C 1.35.2), containing pencil sketches for all three movements, is written on type 127 paper (September 1940-July 1941); it is located amidst a large group of sketches for Britannia: A Joyful Overture (45), a work known to have been completed in February 1941. On Archer's 1959 list, the work is dated 1944.

Première: The program is dated "Saturday March 1"; reviews appear in The Montreal Daily Star, 3 March 1941, 12, and in The Diapason 32, no. 5 (1941): 22.

One movement: Allegro con brio.

For orchestra (2+pic.2.2.2 $\ 4.3 .3 .1 \backslash$ timp, snare drum, triangle, bass drum, cymbals \strings) / Program note, pasted into A 21.1: "[The work] is based ... 
on the tune 'Rule Britannia,' along with two Canadian folk songs, 'V'la l'bon vent,' and 'Vive la Canadienne.' None of these tunes are quoted, but merely hinted at." / Availability: Ms, A 21.1; Edwin A. Fleisher Collection of Orchestral Music, in the Free Library of Philadelphia / Première: BBC Home Service broadcast, 19 March 1942 (BBC Orchestra; Adrian Boult, conductor), on a program of Canadian music / On the cover of Ms A 21.1: "Dedicated to Douglas Clarke, Dean of Music, McGill University, Conductor of the Montreal Orchestra" / Hartig W3.

Date of composition: The ink score (A 21.1) is dated February 1941.

Première: Data from Radio Times (BBC), 13 March 1942, 15; and from The Standard (Montreal), 11 April 1942, Editorial and News Section, 5. These reports do not state explicitly that the performance was the première; the Radio Times does not address the matter, and The Standard is ambiguous, stating that Archer's "composition, Britannia: A Joyful Overture, was performed for the first time in Great Britain by the B.B.C. Orchestra. ..." However, an announcement of the performance of Britannia conducted by Percy Grainger in Toronto on 21 May 1946, printed in The Monitor (Montreal), 16 May 1946, 9, is quite clear: “... this will mark its première on this continent. It was first performed by the BBC Orchestra in London, England. ..."

\subsection{Britannia: A Joyful Overture. February 1941.}

One movement: Allegro con brio.

Arrangement for two pianos of the orchestral work / Availability: Ms, C 1.37.2 / Not in Hartig.

Status and date of the arrangement: Britannia was extensively revised after composition was completed. Three scores of the early version exist, a pencil orchestral score (A 3.33) and pencil and ink scores (A 3.9, C 1.36) of the two-piano arrangement. However, all of these scores are incomplete, about one-third of their pages having been reused in the scores of the final version, the pencil orchestral score (C 2.1), and the pencil and ink scores (C 1.37.1, C 1.37.2) of the arrangement. A substantial group of sketches and drafts (C 1.35.1), and the ink score (A 21.1) of the final version, dated February 1941, complete the array of sources. The sketches and drafts are written principally on type 126 paper (September 1940-March 1941), along with one folio of type 127 (September 1940-July 1941) and four half-folios that could be either type; all of the scores of the two-piano arrangement are on type 127. The arrangement of the final version could thus have been completed as late as July 1941 . But the fact that scores of the arrangement exist for the early version suggests that the two-piano transcription was part of the overall scheme and probably prepared at the same time as the orchestral original. The arrangement was clearly viewed as secondary: the caption of $\mathrm{C}$ 1.37.1 reads "Britannia: A Joyful Overture (for full orchestra). Reduction for two pianofortes," and of C 1.37.2 "Britannia: A Joyful Overture. Two-piano transcription." Nevertheless, it was intended to be performed; the existence of a short score draft (C 1.35.1) in addition to the arrangement suggests that the arrangement is not merely a composing score subsequently orchestrated; and Helmut Kallmann's list of Archer's works in his Catalogue of Canadian Composers (Toronto: CBC, 1952 ) states that the work is for "orchestra (or 2 pianos)."

\section{Motet Written for a Specialle Occasion. March 1941?}

One movement: With dignitie, "Happy birthday to you."

For SATB choir unaccompanied / Based on the melody "Happy birthday to you," used as a cantus firmus in the tenor part / Availability: Ms, A 3.43.1 / Possibly written for the shared birthday of Douglas Clarke and Reginald de Haviland Tupper, 4 April 1941 / Not in Hartig.

Date of composition: Both of the extant scores (A 3.14, A 3.43.1) are undated and written in ink on type 127 paper (September 1940-July 1941). 
47 Birthday Fugue à la Weinberger. March 1941 ?

One movement: With a gay dancing rhythm.

For two pianos / Based on the melody "Happy birthday to you" / Availability: CMC / Première: Victoria, BC, 11 May 1964 (Patricia Elliott, Jocelyn Pritchard) / On the title page of Ms A 3.4.2: "To D. C. and R. de H. T. (Douglas Clarke, Dean, McGill Conservatorium of Music; Reginald de H. Tupper, Vice-Director, McGill Conservatorium of Music), both of whose birthdays fall on the same day [4 April]." / Recording: University of Alberta Music Library concert tape, 24 April 1993, from a concert at the University on that date celebrating the eightieth birthday of Violet Archer (Stéphane Lemelin; Milton Schlosser) (2:12) / Hartig W215.

Date of composition: Both of the extant manuscript scores (A 3.4.1, A 3.4.2) are undated and written in ink on type 127 paper (September 1940-July 1941). The work may have been written for the shared birthday of the dedicatees on 4 April 1941. On Archer's 1959 list, it is dated 1946.

Première: As reported in Pan Pipes 57, no. 2 (1965): 44. It does seem likely that the work was performed in Montreal on or about 4 April 1941, possibly by Archer and her friend the pianist William Stevens (the name "Bill" is pencilled on the title page of Ms A 3.4.1). But this is sheer speculation.

The Ship of Rio. March 1941.

One movement: Vigorously, but not too fast, "There was a ship of Rio sailed out into the blue."

Song for boys voices in unison (b-e2) and piano / Poem by Walter de la Mare, from Peacock Pie: A Book of Rhymes (New York: Henry Holt, 1924), $21 /$ Availability: Ms, A 12.31, A 14.39, A 14.47 and A 14.48 / Hartig W198.

Date of composition: The earliest extant score (A 18.47), with the vocal line in ink and the accompaniment in pencil, is dated March 1941, as are two of the ink scores (A 14.39, A 14.48).

Some One. March 1941.

One movement: Leisurely, "Some one came knocking at my wee small door."

Song for children's voices in unison or medium voice solo (b-e2), with piano / Poem by Walter de la Mare, from Peacock Pie: A Book of Rhymes (New York: Henry Holt, 1924), 15 / Availability: Ms, A 14.38, A 14.49 and A 18.64 / Earliest known performance: Denton, Texas, 28 February 1951 (Barbara Stevenson, soprano; Violet Archer, piano), on a recital of Archer's compostions at North Texas State College / Hartig W203 (solo voice); W151 (unison voices).

Date of composition: The earliest scores (A 14.38, A 14.49, A 18.64) are all written in ink on type 127 paper (September 1940-July 1941); the first two of these are dated March 1941.

Earliest known performance: Program.

49.1 Some One. Revised June 1959.

One movement: Leisurely, "Some one came knocking at my wee small door." 
Song, revised version, for children's voices in unison or medium voice solo (b-e2), with piano / Availability: Waterloo, Ont.: Waterloo Music, 1976 / Hartig W203 (solo voice); W151 (unison voices).

Date and extent of revision: A change to the rhythm of the vocal line in measures 13 and 14 seems to have been made in 1947 or 1948, when the work was first copied onto a transparency (A 17.58). A more extensive revision, involving the thinning of the texture of the accompaniment but no recomposition, is noted in pencil on one of the ink scores (A 14.38) of the original version and incorporated into a score (A 12.65) written on transparencies of a type used for fair copies of works composed in 1958 and 1959. On Archer's 1959 list of her works, a handwritten addition to the entry for this work reads "Revised June 1959."

Title: The title of the published poem is "Some One." This version is used in all of the manuscript sources of the song, but not in the published score, where the title, both on the title page and in the caption, is "Someone." Similarly, the published poem begins "Some one came knocking ..."; several of the manuscripts use this version. But in other manuscripts and in the published score the two syllables are separated by a hyphen, suggesting the one-word spelling "Someone."

Medium of performance: In the earliest scores (A 14.38, A 14.49, A 18.64), the caption includes "a song for children" or a similar phrase; the vocal staff is labelled "unison" in A 18.64, but has no label in the others. In a score (A 14.32) written several years later, perhaps in 1946, the phrase "a children's song" is retained, but the label on the vocal staff is changed to "voice." Neither indication was included on the earliest transparency (A 17.58), and neither one reappears in subsequent copies. In the published score, the title page includes the words "for voice and piano."

\section{Variations on the French-Canadian Folk Song "Isabeau s'y promène." March 1941. \\ 1 Theme: Larghetto. \\ 2 Variation 1: Meno mosso. \\ 3 Variation 2: Tranquillo, con poco moto. \\ 4 Variation 3: Allegro risoluto. \\ 5 Variation 4: Presto gioioso. \\ 6 Variation 5: Allegro - legatissimo. \\ 7 Variation 6: Lento, come romanza - sognando. \\ 8 Variation 7: Allegretto - scherzando. \\ 9 Variation 8: Finale: Allegro.}

For piano / Availability: Ms, A 4.25 / Première: Montreal, 25 November 1942 (Violet Archer, piano), on the twelfth of the Sarah Fischer Concerts / Hartig W285.

Date of composition: Both the pencil (A 12.109) and ink (A 4.25) scores are dated March 1941.

Première: Program.

51 Three Sketches. April 1941.

1 Little Prelude: Allegretto e leggiero.

2 Impromptu-Slow Dance: Lento sognando.

3 Gigue Scherzo: Allegretto capriccioso.

For two pianos / Availability: Waterloo, Ont.: Waterloo Music, 1979 / Earliest known performance: New York, 31 October 1949 (Evelyn Eby, Reginald Bedford), in a concert at Town Hall / Recording: University of Alberta Music Library concert tape, 4 March 1984 (Alexandra Munn, Ernesto Lejano) (10:00) / Hartig W276. 
Date of composition: Archer's files include two folders (A 12.95.5, A 18.32.5) that were apparently once used as covers for scores of the Three Sketches. In each case, the outside of the folder is arranged as a title page, giving the title and composer's name, and the date April 1941. (The folders now enclose unrelated groups of scores, beginning with A 12.96 and A 18.33.) Only two manuscripts of the work are extant, both undated; a pencil score (A 3.1) of the first movement is written on type 127 paper (September 1940-July 1941), and an ink score (A 4.21) of the complete work on 1 folio of type 127 and 6 of type 129 (March-July 1941). On Archer's 1959 list, the work is dated 1947.

Earliest known performance: Data from program, which states "first performance, U. S."

\subsection{Three Sketches. Between April 1941 and 16 July 1941; May 1941?}

1 Little Prelude: Allegretto e leggiero.

2 Impromptu - Slow Dance: Lento - sognando.

3 Gigue Scherzo: Allegretto capriccioso.

Arrangement for harp and string quartet / Availability: Ms, A 13.89, A 13.90, A 13.92 (movements 1-3 respectively) / Première: Montreal, on the "Salon Music" program broadcast over radio station CBM on 16, 17, and 18 July 1941, one movement each evening (performed by "an orchestra under the direction of Alexander Brott") / Not in Hartig.

Date of arrangement: The scores of the three movements (A 13.89, A 13.90, A 13.92) are all on type 130 paper and were probably written in April or May 1941 (see note on type 130). The harp part (C 2.19) is written on one folio of type 127 (September 1940-July 1941) and one of type 129 (March-July 1941), and the string parts (movements 1 and 2, A 3.47; movement 3, A 13.92) on type 132 (July 1941-March 1942). Thus the parts appear to have been written rather later than the scores, perhaps when the July performance was scheduled.

Première: Data from an announcement in The Gazette (Montreal), 16 July 1941, 2. An article in The Montreal Daily Star (17 July 1941, 15) reports on the first broadcast and announces the two that remained. It names the works and describes them as "three new compositions by Miss Violet Archer" but does not mention the performers.

\subsection{Two Sketches. May 1941 ?}

1 Little Prelude: Allegretto e leggiero (1.1.1.0 \0.0.0.0 \triangle \ strings).

2 Impromptu Slow Dance: Lento - mystico (1.1.1.0 $\backslash 0.0 .0 .0 \backslash$ piano or harp \strings).

Arrangement for orchestra of movements 1 and 2 of Three Sketches / Availability: Ms, A 13.91 / Not in Hartig.

Date of arrangement: The only extant score is written in pencil on type 130 paper (May?-July 1941). An incomplete set of parts (A 13.93: Oboe, Violin I, Violin II, Viola, Cello; A 2.41: Flute) is written in pencil on type 133 paper (March-December? 1942).

\section{Intermezzo for Harp. July 1941.}

One movement: Andantino - piacevole. Availability: Ms, A3.2 / Not in Hartig.

Date of composition: The only extant score (A 3.2), in pencil, is dated July 1941.

Title: Archer's 1952 and 1957 lists of her works both include the entry "Little Prelude for Harp" as does the list published in Helmut Kallmann's Catalogue of Canadian Composers (Toronto: CBC, 1952). Since no entry for the present Intermezzo appears on any of those lists and no score of a work with the title "Little Prelude" has been located, it is possible that the entries refer to the Intermezzo. 
53 Fantasia Concertante. July 1941.

One movement: Adagio.

For flute, oboe, clarinet, and string orchestra / Availability: Toronto: Berandol Music, 1979; study score has publisher's no.: BER 1792) / Première: Edmonton, 20 October 1974 (Joan Pecover, flute; Dayna Fisher, oboe; Ernest Dalwood, clarinet; a string orchestra; Malcolm Forsyth, conductor), on a program at the University of Alberta / Recording: University of Alberta Music Library concert tape, 20 October 1974, from the première performance (9:56) / Hartig W13.

Date of composition: The pencil score (A 19.11) is dated July 1941.

Première: Data from program. The performance is described as a première in reports in Pan Pipes 67, no. 2 (1975): 44, and in Music Scene, no. 281 (January/February 1975): 16. The program of a later Edmonton performance, on 20 October 1985, states that the work was premièred in Montreal in 1941, but this is not substantiated by any program or press clipping in Archer's files.

\section{Three Preludes for Piano. July 1941?}

1 Allegretto - scherzando. Between July 1941 and March 1942.

2 Lento - come elegia. July 1941.

$3 \quad$ Allegro appassionato. Between July 1941 and March 1942.

Nos. 1, 3, and 6 of Six Preludes. Nos. 2, 4, and 5 were composed later, possibly in 1947; the six were then distributed together, and ultimately published in a single volume / Availability: In Six Preludes, Piano. Waterloo, Ont.: Waterloo Music, 1979 / Earliest known performance: No. 1: New York, 16 July 1950 (Violet Archer), a performance of nos. 1, 5, and 4 from Six Preludes, broadcast over radio station WNYC. No. 3: Boston, 23 November 1952 (William Stevens), a public performance of nos. 1, 5, 4, and 6 from Six Preludes, under the title "Four Moods." Nos. 1-3: A broadcast performance of Six Preludes, on the CBC program "Première," 20 December 1954 (Rose Goldblatt) / Recording: University of Alberta Music Library concert tape, 17 September 1977, a performance of Six Preludes, recorded at a concert given during the organizational meetings of the Alberta Composers Association, held at the University of Alberta (performer not known) (1:40, 4:46, 1:06) / Hartig W261. Date of composition: The extant manuscripts are all written on type 132 paper (July 1941-March 1942), a pencil score of each Prelude (A 14.15, A 3.5, A 12.100), an ink score of the first (A 12.105), and two of the second (A 12.101, A 12.104). A 12.101 is dated July 1941; all of the others are undated.

Performances: Data on the three perfomances come, respectively, from a WNYC program sheet and a program of Stevens's Boston recital, both in Archer's files, and from Pan Pipes 48, no. 2 (1956): 34 . None of these sources describes the performance as a première.

Psalm 150. July 1941?

One movement: Largo maestoso, "O praise God in His holiness." Anthem for SATB choir (A divisi) and organ / Text: Psalm 150 (complete), in an unidentified twentieth-century translation / Availability: Waterloo, Ont.: Waterloo Music, 1965 / Première: Oklahoma City, 12 February 1956 (Westminster Presbyterian Church Choir; James McGoughie, conductor), on the occasion of the church's tenth anniversary / Hartig W144. 
Date of composition: Two manuscripts are extant, an incomplete pencil draft (A 2.42) on a half-folio that is probably type 127 (September 1940-July 1941), but possibly type 126 (September 1940-March 1941), and a pencil score (A 3.28) on one folio of type 132 (July 1941-March 1942). On Archer's 1959 list, the work is dated 1941.

Première: Data from Pan Pipes 49, no. 2 (1957): 34, and from a copy of Westminster News found in Archer's files, 2, no. 24 (10 February 1956): 13. The performance is noted in the "Premières" section of the report in Pan Pipes; the date given there, 10 February 1956, is incorrect.

\section{Concertino for Clarinet in A and Orchestra. October 1941.}

1 Allegretto scherzoso (solo clarinet $\backslash 1+$ pic.1.0.1 $\backslash 0.1 .0 .0 \backslash$ strings).

2 Lento e mesto (solo clarinet $\backslash$ strings).

3 Allegro ma non troppo (solo clarinet $\backslash 2+$ pic.2.1.2 $\backslash 2.2 .0 .0 \backslash$ strings). Availability: CMC; performance materials available on rental from Berandol Music, Toronto / Première: Winnipeg, 29 February 1972 (Leslie Mann, clarinet; CBC Winnipeg Orchestra; Eric Wild, conductor), a studio recording broadcast over the CBC FM network on 9 March 1972 / Recording: CMC tape $\mathrm{T} 702$, from the broadcast of the première (18:00) / Hartig W5.

Title and date of composition: The pencil (C 2.2.1) and ink (A 19.14) orchestral scores are both dated October 1941. On Archer's 1959 list, the work is dated 1946, a date which is repeated in the CMC Catalogue of Canadian Music for Orchestra (1976) and several other published lists. That Catalogue also refers to a 1956 revision, of which no evidence has been found amongst Archer's scores. An entry in the CMC accession list for the period 1 December 1970 to 30 September 1971 (Music Scene, no. 262 [November/December 1971], 14), "Concerto for Clarinet in A and Orchestra (1971)," appears to refer to the Concertino, as there is no other evidence of a concerto composed in 1971. A copy (A 19.13) of the Concertino, reproduced from a copyist's transparencies, was shipped from the CMC to Archer on 7 June 1971, according to a shipping form filed with the score, and there is other evidence that makes it reasonable to suppose that the transparencies were deposited in the CMC Library earlier that year. According to documents in Archer's files, she registered the Concertino with PRO Canada on 14 June 1971, corresponded with the CMC in December 1971 regarding the copying of parts for the première, and signed a rental agreement with Berandol Music on 28 December 1971. The erroneous entry in the CMC accession list is no doubt the source of the entry for a "Clarinet Concerto (1971)" in the list of Archer's works in the seventh and eighth editions of Baker's Biographical Dictionary of Musicians (New York: Schirmer Books, 1984, 1992).

Tempo indication: In the CMC score, the tempo indication for the first movement is "Allegretto scherzo." This is no doubt an error; the CMC clarinet part has "Allegretto scherzoso," as do all of the manuscript sources.

Première: As reported in Pan Pipes 65, no. 2 (1973): 39 and in Music Scene, no. 265 (May/June 1972): 22. The recording date is supplied by the catalogue of the CMC sound recordings collection and by a letter to Archer from Henry Mutsaers, librarian of the Canadian Music Centre, dated 20 December 1971, relating to the preparation of the parts.

\section{The Tragedy of Syllabus and Diapason. December 1941?}

Incidental music for a skit written by William Stevens / Availability: No score extant; script, A 3.57 / Earliest known performance: Montreal, December 1941, at the Christmas party of the McGill Conservatorium Club / Not in Hartig.

Date of composition: An undated newspaper clipping in Archer's files, possibly from the McGill Daily, announces that "The McGill Conservatorium Club will hold their annual Christmas party this coming Friday December 18. ... The main feature of the evening will be a skit by Bill Stevens, with incidental music by Violet Archer. The skit ... is the well-known 'Greek Tragedy' which was given last year." Of the years between Archer's graduation from high school and her departure from Montreal, the date is consistent with 1931, 1936, and 1942. Archer's sketches (C 1.34) for another 
of Stevens's skits are written on two half-folios, one of type 132 or 133 paper (July 1941-December? 1942) and one of type 134 (January 1943-early 1946?), suggesting that these collaborations took place in the early 1940s. Accordingly, it seems likely that the party announced in the clipping took place in December 1942, and the "Greek Tragedy" was introduced the previous year.

$58 \quad$ Fantasy for Clarinet and String Orchestra. Between September 1941 and March 1942; early 1942?

One movement: Larghetto.

Availability: CMC / Première: Montreal, 21 May 1942 (Jean Charles Lafontaine, clarinet; McGill Conservatorium Orchestra; Violet Archer, conductor) / Recording: University of Alberta Music Library concert tape, 1 December 1983 (Daniel Sutherland, clarinet; Academy Strings; Norman Nelson, conductor) (6:35) / Hartig W14.

Date of composition: All of the manuscripts are undated. The two scores (A 18.69 in pencil, A 2.27 in ink) are written on type 132 paper (July 1941-March 1942), as is a pencil score (A 1.36) entitled "Canzona" consisting of measures 1-50 in an arrangement for clarinet and piano. At the foot of the first page of the ink score is the address 3446 Décarie Boulevard; this appears to have been written at the same time as the music. If that is so, the score could not have been copied before September 1941. A set of four parts (A 3.34: Violin I, Violin II, Viola, Cello) is written in ink on type 133 paper (March-December? 1942). Of Archer's own lists, the Fantasy is mentioned only on the one compiled in 1957, which lacks dates of composition.

Première: Data from program. Two reviews (The Montreal Daily Star, 23 May 1942, 20; The Standard (Montreal), 23 May 1942, Editorial and News Section, 9) both describe the Fantasy as a "new work." The Standard names Lafontaine as soloist and Archer as conductor; The Star names Lafontaine, but does not mention the conductor. The CMC Catalogue of Canadian Music for Orchestra (1976) states that the première took place in 1942, with Raizel Frank, clarinet, The McGill Conservatorium Orchestra, and Reginald de Haviland Tupper, conductor. No program has been located in Archer's files or in the Archives of McGill University to verify this information. A performance with Frank as soloist may have taken place later in the year, but in view of the description of the Fantasy as a "new work" found in reviews of the 21 May performance, it seems unlikely that such a performance took place earlier.

\subsection{Fantasy for Violin and Piano. Late 1946?}

One movement: Larghetto.

An arrangement of the Fantasy for Clarinet and String Orchestra / Availability: CMC / Earliest known performance: New Haven, 12 May 1948 (Reinhard Pauly, violin; Esther Franck, piano) / Hartig 46.

Date of arrangement: On p. 23 of Compositeurs canadiens contemporains (Montreal: Presses de l'Université du Québec, 1977), it is stated that the arrangement was made in 1946 and first performed that year on a CBC broadcast from Montreal by Ethel Stark, violin, and Violet Archer, piano. Correspondence in Archer's files makes it clear that she herself supplied this data for the 1977 publication, providing it to the CMC some time in 1976; whether it was based on documentation or recollection is not clear. In depositing a pencil score (C 2.8) at the University of Calgary in 1980, she again supplied 1946 as the date of the arrangement. Other evidence tends to confirm this date. The pencil score (C 2.8) is written on a type of paper that was probably introduced early in 1944 during the composition of the Symphony and that remained available through the end of 1948. In the copies available at the CMC (also at A 7.12), the part is written on a type of transparency first used in the course of preparing the score of the orchestral Fantasy on a Ground (known to have been composed in 1946 before October) and superseded by fall 1947. The Fantasy for Violin and Piano does not appear in A List of Canadian Music (Toronto: Oxford University Press, 1946), nor is it mentioned in the article "Canada's Coming Woman Composer" by Winifred E. Wilson (Canadian Home Journal 43, no. 6 (October 1946): 2, 28). While the latter publication makes no 
attempt to provide a complete list of works, it does mention most works composed in the preceding five years, making it at least probable that the Fantasy was arranged after that article went to press.

Earliest known performance: Program.

Sonata for Piano No. 1. April or May 1942.

1 Jubilante e ritmico.

2 Larghetto commodo.

3 Allegretto grazioso.

Availability: CMC / Première: CBC broadcast, on the program "Première," 2 January 1956 (Josephte Dufresne) / Recordings: CMC tape T 1796, from a CBC broadcast, 19 September 1957 (Rose Goldblatt Finkel, piano) (15:15). University of Alberta Music Library concert tape, 28 February 1978 (Albert Krywolt, piano) (13:40) / Hartig W263.

Date of composition: The manuscript sources consist of a pencil score (A 3.20) written on one folio of type 132 paper (July 1941-March 1942) and six and one-half folios of type 133 (March-December? 1942), and an ink score (A 4.22) written entirely on type 133; both are undated. Thus it is probable that the Sonata was composed at some time after the completion of the first movement of the Quartet for Flute, Oboe, Clarinet, and Bassoon (60), whose ink score (A 15.73) is written entirely on type 132 paper and dated March 1942. And it appears that the Sonata was completed before work began on the fourth movement of the Quartet, at some time prior to 5 June 1942 (see note on the Quartet). On Archer's 1959 list, the Sonata is dated "1945 revised /57."

Revision: Like Archer's 1959 list, the CMC Canadian Keyboard Music Catalogue notes that the Sonata was revised in 1957. The score in the CMC Library is in Archer's hand, reproduced from transparencies of a type that she used in the period 1955-60. It seems likely therefore that the revision was undertaken when the transparencies were prepared. Comparison of this score with the ink manuscript (A 4.22) reveals some editing of indications of dynamics and articulation but no alterations of a more fundamental nature.

Première: As reported in Pan Pipes 49, no. 2 (1957): 34.

Quartet for Flute, Oboe, Clarinet, and Bassoon. May 1942.

1 Allegretto giocoso. March 1942.

2 Lento. March 1942.

3 Tempo di minuetto. March 1942.

4 Allegretto piacevole. April or May 1942.

Availability: Ms, A 13.88 / Première (movements 1-3): Montreal, 13 April 1942 (Ralph Moore, flute; Peter Masella, oboe; Raizel Frank, clarinet; Wayland Mowsher, bassoon), on a program sponsored by the B'nai B'rith Music Group (Mt. Royal Chapter no. 21), with "total proceeds to war efforts"। Hartig W67.

Date of composition: Both the pencil (C 2.7.1) and ink (A 15.73) scores of the first movement are written on type 132 paper; the ink score is dated March 1942. The pencil scores (C 2.7.2, C 2.7.3) of movements 2 and 3 are written on the successor paper, type 133, but must have been completed in time for rehearsals for the première. The fourth movement was drafted (A 13.95) on half-folios of type 133 paper. One leaf from this group contains the beginning of an ink score of the Sonata for Piano No. 1. The score was abandoned, perhaps because of a copying error, and the leaf reused in the draft of the Quartet, suggesting that the Sonata was complete at the time the fourth movement of the Quartet was being composed. On another leaf is written what appears to be a memorandum of an up-coming appointment, "Friday June 5th, 4 pm." The date is consistent with 1942 and suggests that the composition of the fourth movement of the Quartet was in progress a short time earlier. The pencil score of the fourth movement (A 3.32) and the ink score of the complete work (A 13.88) are 
both written on type 133 paper (March-December? 1942). On Archer's 1959 list of her compositions, this work is dated 1945.

Première: The program identifies the sponsor, the occasion, and the performers; it is, however, undated and lists Archer's work as "Three Divertimenti." The date is supplied by an announcement in The Montreal Daily Star, 13 April 1942, 6. The "Three Divertimenti" can be identified with the woodwind Quartet by their instrumentation and by the fact that the pencil scores (C 2.7) of the first three movements of the Quartet have the captions "Divertimento I," "Divertimento II," and "Divertimento III." These titles had been abandoned by the time the complete ink score (A 13.88) was prepared. A letter in Archer's files, dated 20 April 1942, written by the president of the sponsoring Music Group, confirms that the performance was the première: it thanks her "for allowing us to have the honour of hearing the first playing of your new work, 'Three Divertimenti'."

\section{Theme and Variations for String Quartet.}

\section{Availability: No score extant / Hartig W101.}

There is no score of this work amongst Archer's papers, either at her home or at the University of Calgary, and no score in the libraries of the Canadian Music Centre. The list of Archer's compositions compiled by George Proctor notes a performance of a string orchestra arrangement of the work in 1943 by the McGill Conservatorium Orchestra under Reginald de Haviland Tupper; however, no program of this performance has been found amongst Archer's papers or in the Archives of McGill University. While the manuscripts may have been lost or destroyed, it seems more likely that references to this work are actually references to the Variations on an Original Theme (20), an orchestral work that also exists in two versions for string orchestra $(20.1,20.2)$, of which one (20.1) was performed by the McGill Conservatorium Orchestra on 10 January 1939, and either could be played by a string quartet. Early lists of Archer's works mention one or both of the works, as follows: Archer's 1940 list: Under the heading Strings: "Variations on Original Theme for String Orchestra." A List of Canadian Music (Toronto: Oxford University Press, 1946): Under the heading Chamber Music: "Variations on an Original Theme."

Wilson, Winifred E., "Canada's Coming Woman Composer" (Canadian Home Journal 43, no. 6 [October 1946]: 2, 28): "Theme and Variations for String Quartet."

Kallmann, Helmut, Catalogue of Canadian Composers (Toronto: CBC, 1952): Under the heading Orchestral works: "Variations on an Original Theme, String Orchestra"; under the heading Chamber works: "Variations on an Original Theme, String Quartet."

Archer's 1957 list: Under the heading Orchestral: "Variations on an Original Theme - String Orchestra"; a handwritten addition under the heading Chamber works: "Theme and Variations, String Quartet."

Archer's 1959 and 1960 lists: Under the heading Chamber Works: "Theme and Variations (String Quartet), 1942."

Perhaps the confusion began with Winifred Wilson's article. While it is clearly based on an interview, Wilson may have used $A$ List of Canadian Music as a memorandum if not as a source: of twenty-one works mentioned in her article and twenty-two on the List, seventeen are common. That total rises to eighteen if, as seems reasonable, one associates Wilson's "Theme and Variations for String Quartet" with the entry "Variations on an Original Theme" in the Chamber Music section of the 1946 List. And because of the wording of the title on the List as well as the absence of any evidence for the existence of an independent work for string quartet, that entry seems more likely to refer to a string quartet performance option for one of the string orchestra versions of Variations on an Original Theme $(20.1,20.2)$ than to a different work.

61 Sonatina for Piano No. 1. Between March and October 1942.

1 Allegretto semplice.

2 Lento pensieroso.

3 Tempo di valse - poco moderato.

4 Allegretto capriccioso. 
Availability: CMC / Première: Montreal, 25 November 1942 (Violet Archer, piano), on the twelfth of the Sarah Fischer Concerts / In Archer's handwriting on one of her copies (A 17.85) of the CMC score: "Dedicated to the distinguished pianist Thelma Johannes O'Neill" / Hartig W266.

Date of composition: The pencil score (C 2.9) is written on four folios of type 133 paper (March-December? 1942). When the manuscript was deposited at the University of Calgary in 1980, Archer supplied 1945 as the date of composition; on her 1959 list as well, the work is dated 1945.

Première: Program.

62 Little Fugue in G Minor for Organ, by J. S. Bach, Arranged for Orchestra. Between May 1941 and early 1944.

One movement: No tempo indication.

Arrangement for orchestra (2.2.2.2 22.2.0.0 \strings) of the Fugue, BWV 578 / Availability: Reproduction of copyist's Ms, A 17.25 / Hartig W22.

Date of composition: The only extant holograph manuscript (A 17.25) is written in pencil on type 131 paper (May 1941-Spring? 1944).

God Save the King. Arrangement for orchestra, third version. Between May 1941 and early 1944. See: 38.2.

O Canada. Arrangement for orchestra, second version. Between May 1941 and early 1944. See: 39.1.

63 Sonata for Flute, Clarinet in A, and Piano. February 1943?

1 Allegretto commodo.

2 Largo tranquillo.

3 Larghetto.

4 Allegretto grazioso.

Availability: CMC / Earliest known performances: CBC broadcast, summer 1945. Montreal, 29 March 1947 (Norman and Gertrude Herschorn, violins; Violet Archer, piano). Denton, Texas, 28 February 1951 (George Morey, flute; Lee Gibson, clarinet; Violet Archer, piano), on a recital of Archer's compositions at North Texas State College / Hartig W82.

Date of composition: The extant manuscripts are all undated. An article in The Montreal Daily Star, 5 March 1943, 20, quotes Archer as follows: "My most recent works are for piano. I played some of them at one of Mme. Sarah Fischer's concerts [25 November 1942; see works 31, 50, and 61]. I have just completed a Sonata for flute, clarinet, and pianoforte." On Archer's 1959 list, this work is dated 1944.

Earliest known performances: The CBC broadcast is mentioned in Frances Goltman's column "Musical Sharps Flats and Naturals" (The Monitor [Montreal]), ca. 23 August 1945) and in the article "Canada's Comig Woman Composer" by Winifred E. Wilson (Canadian Home Journal 43, no. 6 [October 1946]: 2, 28), but it has not been possible to document the broadcast more precisely. Data on the 1947 and 1951 performances come from the respective programs. There is little doubt that the Sonata for Two Violins and Piano, performed on 29 March 1947, is in fact the present work. The tempo marks given in the program match those of the Sonata for Flute, Clarinet, and Piano; Archer's files include a copy of the flute part (A 15.75) that has been bowed by a violinist, and a copy of a Violin II part (A 2.47), written on paper of a type used from early 1944 through 1948, which is a substitute for the clarinet part. George Proctor's list of Archer's works states that the 
première of the Sonata was given in Montreal in 1942, by Ralph Moore, flute, Raizel Frank, clarinet, and Violet Archer, piano. And indeed, Archer has stated, in a verbal communication to the writer, that she composed the Sonata for Moore and Frank, but it has not been possible to document the performance mentioned by Proctor.

\begin{abstract}
This chronological catalogue of Violet Archer's earliest completed compositions, including works written from 1932 to 1943, is based on manuscripts in her possession and on deposit at the University of Calgary Library, as well as published scores and reproductions of manuscripts in the University of Alberta Library and the libraries of the Canadian Music Centre. It provides the date of composition for each work and summarizes the supporting evidence, including dates found on manuscripts, the types of paper used, entries on lists of works compiled by the composer, and dates of first and early performances. Also included are the medium of performance of each work, a list of movements, the source of any text, and the location of scores and recordings.
\end{abstract}

